Melina Gouveia Castro

\title{
A influência da introdução de um programa de educação médica em terapia nutricional no desfecho dos pacientes em uma unidade de terapia intensiva
}

\author{
Tese apresentada à Faculdade de Medicina da \\ Universidade de São Paulo para obtenção do título de \\ Doutor em Ciências.
}

Programa de: Ciências em Gastroenterologia

Orientador: Prof. Dr. Dan Linetzky Waitzberg

SÃo PAULO

2012 
Melina Gouveia Castro

A influência da introdução de um programa de educação
médica em terapia nutricional no desfecho dos pacientes em uma unidade de terapia intensiva

Tese apresentada à Faculdade de Medicina da Universidade de São Paulo para obtenção do título de Doutor em Ciências.

Programa de: Ciências em Gastroenterologia

Orientador: Prof. Dr. Dan Linetzky Waitzberg

SÃo PaUlo

2012 
Dados Internacionais de Catalogação na Publicação (CIP)

Preparada pela Biblioteca da

Faculdade de Medicina da Universidade de São Paulo

Creprodução autorizada pelo autor

Castro, Melina Gouveia

A influência da introdução de um programa de educação médica em terapia nutricional no desfecho dos pacientes em uma unidade de terapia intensiva / Melina Gouveia Castro. -- São Paulo, 2012.

Tese(doutorado)--Faculdade de Medicina da Universidade de São Paulo. Programa de Gastroenterologia.

Orientador: Dan Linetzky Waitzberg.

Descritores: 1.Educação nutricional 2.Terapia nutricional 3.Nutrição parenteral 4.Nutrição enteral 5.Unidades de terapia intensiva

USP/FM/DBD-068/12 


\section{Dedicatóría}

"É na educação dos filhos que se revelam as virtudes dos pais."

Coelho Neto

Dedico esta tese aos meus pais Regina e Mílton, por todo amor e esforço para minha formação. Ao meu marido Luis Fernando, pela compreensão e apoío, è minha fílha Bruna, minha inspíração. 


\section{Agradecimentos}

- Ao meu orientador, Prof. Dr. Dan Waitzberg, toda minha gratidão e admiração: você é meu exemplo de profissional $e$ cientista.

- Ao Dr. Carlos Eduardo Pompilio, por toda amizade, ajuda, paciência e atenção a mim dispensada desde o início deste projeto.

- À minha grande amiga, tutora e "ajudante" Lilian Mika Horie, por toda ajuda com esta tese desde o primeiro dia.

- A toda minha família, em especial, a minha tia e madrinha Vera Lucia Dabul Gouveia, que sempre esteve presente em todos os momentos.

- A todos meus amigos da Faculdade de Medicina do $A B C$, em especial, Heloisa Amaral Gaspar, Rafaela Sarmento Pereira, 
Patrícia Santi, Renato Prescinotto e Fabiola Suano, que se tornaram parte de minha família.

- A todos meus amigos do GANEP, em especial, Dra. Maria de Lourdes Teixeira da Silva, Juliana Renófio, Patrícia Morais de Oliveira, Renata Cristina Campos Gonçalves, Gabrielle Carassini Costa, Viviane Chaer Borges Hafez, Maria Izabel Lamourier de Vasconcelos e Maria Tereza Ferrini, pela amizade e apoio.

- À minha amiga Cristiane Comerom Gimenez Verotti, companheira de créditos e colaboradora neste trabalho.

- A todos os alunos, residentes e estagiários, que foram sempre um incentivo para meu aprendizado. 


\section{NORMATIZAÇÃO ADOTADA}

Esta dissertação está de acordo com as seguintes normas, em vigor no momento desta publicação:

Referências: adaptado de International Committee of Medical Journals Editors (Vancouver)

Universidade de São Paulo. Faculdade de Medicina. Serviço de Biblioteca e Documentação. Guia de apresentação de dissertações, teses e monografias. Elaborado por Annelise Carneiro da Cunha, Maria Julia A. L. Freddi, Maria F. Crestan, Marinalva de Souza Aragão, Suely Campos Cardoso, Valéria Vilhena. $2^{a}$ ed. São Paulo: Serviço de Biblioteca e Documentação; 2005.

Abreviaturas dos títulos dos periódicos de acordo com List of Journals Indexed in Index Medicus. 


\section{SUMÁRIO}

LISTA DE ABREVIATURAS, SIGLAS E SÍMBOLOS

LISTA DE FIGURAS

LISTA DE TABELAS

LISTAS DE QUADROS

RESUMO

SUMMARY

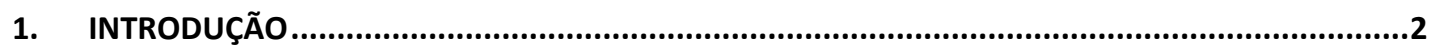

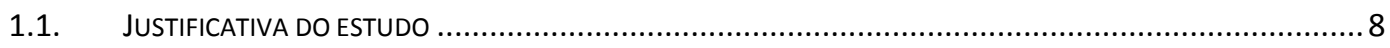

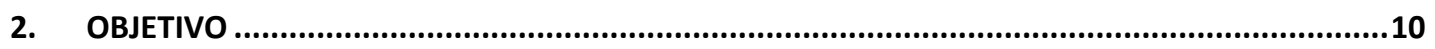

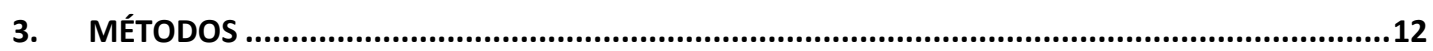

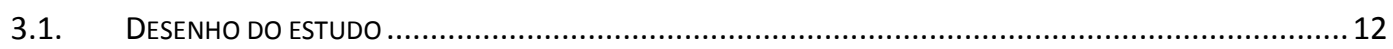

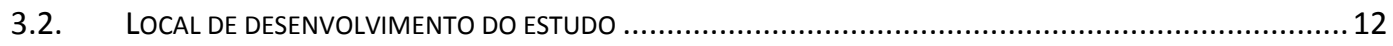

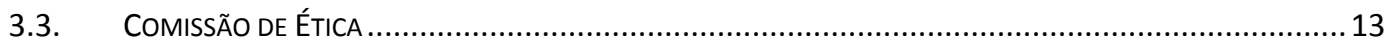

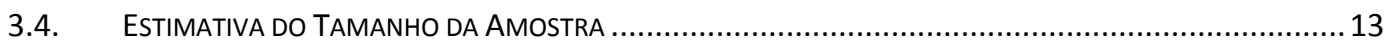

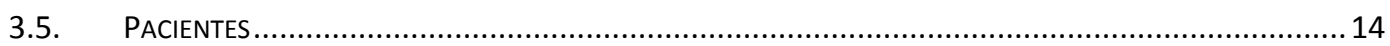

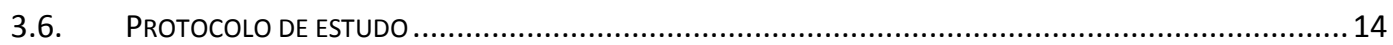

3.6.1. Fase 1 - Pré-programa educacional em TN (PP) ................................................. 14

3.6.2. Fase 2- Programa Educacional em TN (PE) ....................................................... 19

3.6.3. Fase 3 Pós- programa educacional em TN (PO) .................................................. 21

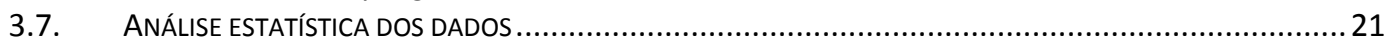

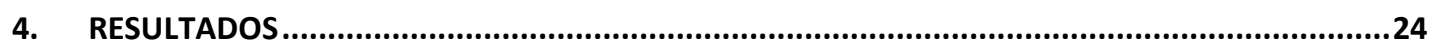

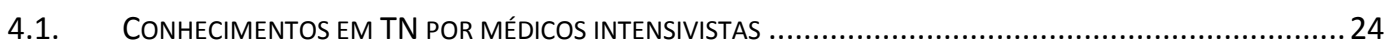

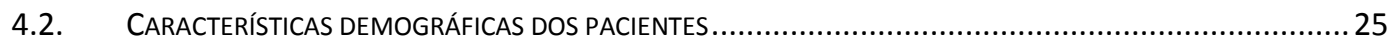

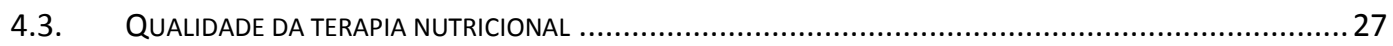

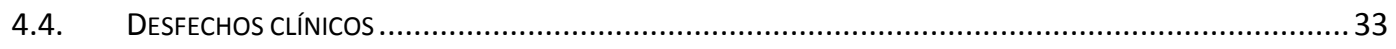

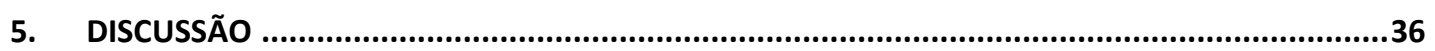

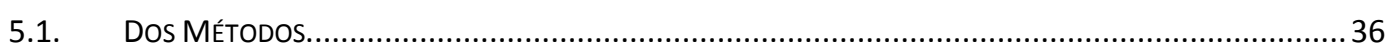

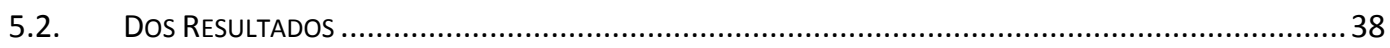

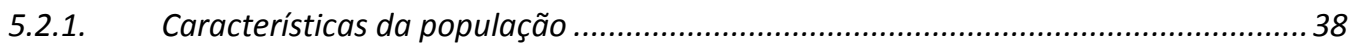

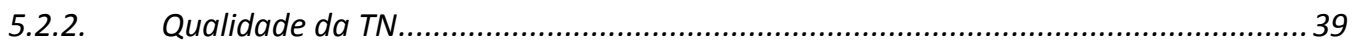

5.2.3. Tempo de permanência na UTI ................................................................... 41

5.2.4. Educação médica em terapia nutricional .......................................................... 43

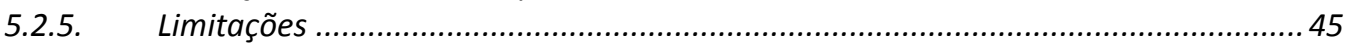

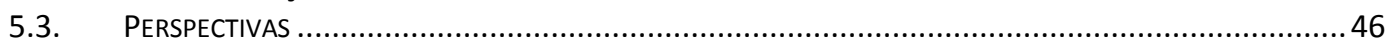

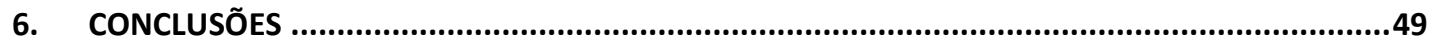

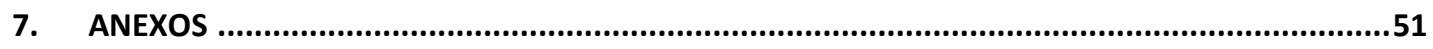

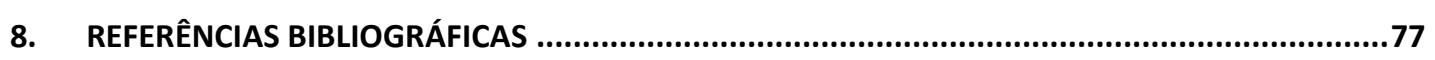

APÊNDICE 


\section{LISTA DE ABREVIATURAS}

A: Altura

ASG: Avaliação Subjetiva Global

AVC: Acidente Vascular Cerebral

DP: Desvio Padrão

E.P.:Erro Padrão

GET: Gasto Energético Total

I: Idade

IMC: Îndice de Massa Corporal

NC: Necessidades Calóricas

Máx: Máximo

Min: Mínimo

NE: Nutrição Enteral

NP: Nutrição Parenteral

\%PP: Percentual de Perda de Peso

P: Peso

PA: Peso Atual

PH: Peso Habitual

PP: Pré-programa de Educação em Terapia Nutricional

PE: Programa de Educação em Terapia Nutricional

Per25: Percentil 25

Per75: Percentil 75

PO: Pós-programa de Educação em Terapia Nutricional 
r: Coeficiente de Correlação

TCLE: Termo de Consentimento Livre e Esclarecido

TN: Terapia Nutricional

TNE: Terapia Nutricional Enteral

TNP: Terapia Nutricional Parenteral

UFC: Unidade Formadora de Colônias

UTI: Unidade de Terapia Intensiva

vs: Versus 


\section{LISTA DE SIGLAS}

APACHE II: Acute Physiology and Chronic Health Evaluation II A.S.P.E.N: American Society of Parenteral and Enteral Nutrition CAPPesq: Comissão de Ética para Análise de Projetos de Pesquisa E.S.P.E.N: European Society of Parenteral and Enteral Nutrition FMUSP: Faculdade de Medicina da Universidade de São Paulo HC-FMUSP: Hospital das Clínicas da Faculdade de Medicina da Universidade de São Paulo

LIM: Laboratório de Investigação Médica 


\section{LISTA DE SÍMBOLOS}

$\%$ : porcentagem

$\geq$ : maior ou igual

s: menor ou igual

$<$ : menor

\pm : mais ou menos

cm: centímetros

dl: decilitros

g: gramas

h: hora (s)

Kcal: quilocalorias

$\mathrm{Kg}$ : quilogramas

$\mathrm{Kg} / \mathrm{m}^{2}$ : quilogramas por metro quadrado

m: metros

ml: mililitros 


\section{LISTA DE FIGURAS}

Figura 1 - Comparação dos acertos obtidos da avaliação de conhecimentos em terapia nutricional aplicada a médicos intensivistas antes e após o desenvolvimento de programa educacional de terapia nutricional. Dados apresentados em média e desvio padrão de acertos

Figura 2 - Dias em jejum (mediana) durante a terapia nutricional entre os pacientes dos grupos pré-programa educacional (PP) e pós-programa educacional (PO). Mann-Whitney, $\mathrm{p}=0,002$ (PP vs PO)

Figura 3 - Quantidade de energia máxima administrada entre os pacientes dos grupos pré-programa educacional (PP) e pós-programa educacional (PO). MannWhitney, $\mathrm{p}=0,001$ (PP vs PO)

Figura 4 - Adequação energética quanto à necessidade energética estimada entre os pacientes dos grupos pré-programa educacional (PP) e pós-programa educacional (PO). Mann-Whitney, $\mathrm{p}=0,001$ (PP vs PO)

Figura 5 - Comparação da via de acesso para terapia nutricional entre os pacientes dos grupos pré-programa educacional (PP) e pós-programa educacional (PO), avaliados por teste qui-quadrado de Pearson

Figura 6 - Tempo de permanência na UTI (dias) entre os pacientes dos grupos pré-programa educacional (PP) e pós-programa educacional (PO). Mann-Whitney, $\mathrm{p}=0,001$ (PP vs PO) 


\section{LISTA DE TABELAS}

Tabela 1 - Características demográficas entre os grupos de pacientes estudados pré-programa educacional (PP) e pós-programa educacional (PO)

Tabela 2 - Resultados da qualidade da terapia nutricional obtidos nos grupos préprograma educacional (PP) e pós-programa educacional (PO) no que se refere à qualidade da terapia nutricional e complicações .......................................................28

Tabela 3 - Modelo de quase-verossimilhança para tempo de permanência em UTI 


\section{LISTA DE QUADROS}

Quadro 1 - Relação dos indicadores de qualidade de terapia nutricional aplicados 16

Quadro 2 - Relação das complicações relacionadas à terapia nutricional avaliadas

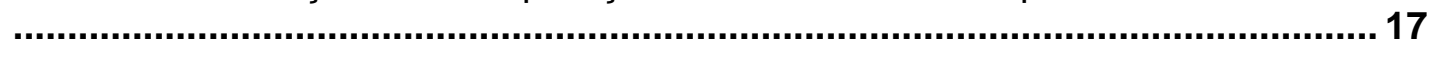

Quadro 3 - Relação dos dados descritivos e clínicos coletados...........................18

Quadro 4 - Relação dos dados nutricionais coletados ........................................19 


\section{RESUMO}

Castro MG. A influência da introdução de um programa de educação médica em terapia nutricional no desfecho dos pacientes em uma unidade de terapia intensiva [Tese]. São Paulo: Faculdade de Medicina, Universidade de São Paulo; 2012.

A terapia nutricional mostra-se de grande importância no tratamento do doente crítico, por apresentar impacto favorável em seu desfecho clínico. No entanto, até $70 \%$ dos pacientes em unidade de terapia intensiva podem não receber terapia nutricional adequada. Isso ocorre, em parte, pela falta de formação e de conhecimento dos profissionais de saúde sobre princípios de nutrição clínica. O objetivo do presente estudo foi avaliar o impacto da introdução de um programa de educação médica em terapia nutricional em uma unidade de terapia intensiva sobre a qualidade da terapia nutricional e os resultados clínicos de seus pacientes. O presente estudo foi desenvolvido em três fases distintas: 1) Pré-programa educacional (PP): 50 pacientes recém-admitidos em unidade de terapia intensiva foram selecionados consecutivamente para avaliação da qualidade da terapia nutricional a eles oferecida e seus desfechos clínicos, através de visitas periódicas. 2) Programa Educacional (PE): foram criados protocolos nutricionais específicos. Um programa de educação em terapia nutricional baseado nesses protocolos (palestras, workshops e discussões à beira leito) foi introduzido nessa unidade de terapia intensiva. 3) Pós-programa educacional (PO): a qualidade da terapia nutricional e os desfechos 
clínicos de um segundo grupo de 50 pacientes foram avaliados, utilizandose a mesma metodologia da fase 1 (PP). Os marcadores utilizados para avaliação da qualidade da terapia nutricional foram: avaliação nutricional, adequação da oferta de energia, tempo de jejum e introdução de nutrição enteral precoce. Tempo de permanência na unidade de terapia intensiva e tempo de internação hospitalar foram registrados e avaliados como desfechos clínicos principais. Os pacientes da fase PP e PO não diferiram em idade, APACHEII, sexo, tipo de diagnóstico na admissão e avaliação nutricional. Observou-se redução no tempo de jejum (PP 3,8 dias $\pm 3,1$ vs PO: 2,2 dias $\pm 2,6 ; p=0,002$ ), melhora na adequação calórica (PP $74,2 \% \pm$ 33,3 vs PO 96,2 $\pm 23,8 \% ; p<0,001$ ) e aumento da indicação de nutrição enteral precoce (PP 24\% vs PO 60\%; $p=0,001$ ) nos pacientes da fase $\mathrm{PO}$, em comparação com os pacientes da fase PP. Além disso, o tempo de permanência na unidade de terapia intensiva foi menor (PP: 21,9 dias \pm 15,2 vs PO: 12,2 dias $\pm 8,0 ; p<0,001)$ nos pacientes da fase $P O$, em comparação com os pacientes da fase PP. Não houve alteração significativa no tempo de internação hospitalar. A introdução de um modelo de educação em terapia nutricional em uma unidade de terapia intensiva melhorou a qualidade da terapia nutricional e diminuiu o tempo de permanência de seus pacientes.

Descritores: Educação nutricional, terapia nutricional, nutrição enteral, nutrição parenteral, unidades de terapia intensiva. 


\section{SUMMARY}

Castro MG. The influence of a medical educational program in nutritional therapy on outcome of critical care patients [Thesis]. São Paulo: "Faculdade de Medicina, Universidade de São Paulo"; 2012.

In critically ill patients, nutritional therapy favorably impacts clinical outcomes. However, up to $70 \%$ of patients in the intensive care unit do not receive adequate nutritional therapy, due, partially, to the lack of training and knowledge regarding nutrition principles among healthcare providers. The aim of this study was to evaluate the impact of a medical educational program in an intensive care unit on the quality of the nutritional therapy and clinical outcomes. The study protocol was developed among three distinct phases: 1) Pre-educational program (Pre-EP): 50 patients newly admitted to the intensive care unit were consecutively selected to assess their regular performed nutritional therapy and clinical end-points. 2) Educational program (EP): specific nutritional protocols were created and an education program (lectures, workshops and bedside discussions) were implemented.

3) Post educational program (Post-EP): a second group of 50 patients was enrolled and observed using the same phase 1 (Pre-EP) methodology. Nutritional therapy practice was evaluated through the application of specific quality indicators and the evaluation of nutritional therapy-related complications, considering as main markers the nutritional assessment, adequacy of energy requirement, duration of fasting and use of early enteral nutrition. Intensive care unit length of stay and hospital length of stay were recorded and measured as primary end-points. The Pre-EP and Post-EP 
patients did not differ in age, APACHEll, gender, admission diagnosis (surgery $\mathrm{x}$ medical) and nutritional assessment. Duration of fasting decreased (Pre-EP 3.8 days \pm 3.1 vs. Post-EP: 2.2 days $\pm 2.6 ; p=0.002$ ), the adequacy of nutritional therapy improved (Pre-EP $74.2 \% \pm 33.3$ vs. Post-EP 96.2\% $\pm 23.8 ; p<0.001$ ) and enteral nutrition was earlier initiated (Pre-EP 24\% vs. Post-E $60 \% ; \mathrm{p}=0.001)$. Intensive care unit length of stay also decreased (Pre-EP: 21.9 days \pm 15.2 vs Post-EP: 12.2 days $\pm 8.0 ; p<0.001$ ). No changes were observed in hospital length of stay. Conclusion: Implementing a medical nutrition educational model in an intensive care unit improved the quality of nutritional therapy and decreased the length of stay of their patients.

Descriptors: Education, nutrition therapy, enteral nutrition, parenteral nutrition, critical care. 
Introdução 


\section{INTRODUÇÃO}

A terapia nutricional (TN) é considerada parte integral do tratamento do paciente crítico, por apresentar impacto favorável no seu desfecho clínico ${ }^{1-4}$. Pacientes críticos que não recebem TN adequada são mais suscetíveis a complicações infecciosas e podem apresentar maior tempo de ventilação mecânica, maior permanência na unidade de terapia intensiva (UTI) e maiores taxas de mortalidade ${ }^{3,5,6}$. Por outro lado, a introdução de nutrição enteral (NE) precoce em pacientes críticos promove redução de pneumonia e mortalidade geral ${ }^{7}$.

A TN no doente crítico busca, além de corrigir deficiências nutricionais, melhorar a imunidade, reduzir o estresse oxidativo, manter a função e a estrutura do trato gastrintestinal e modular favoravelmente a resposta inflamatória ${ }^{3,8}$.

Consensos internacionais, baseados em evidências científicas, estabeleceram as recomendações atuais para a prática da TN em UTI ${ }^{3,6-7}$. Entretanto, observa-se inadequação entre as recomendações e a prática clínica diária, já que a quantidade de pacientes críticos que recebem TN adequada pode variar de 14 a $67 \% \%^{3}$.

Um estudo francês revelou discrepância de $29 \%$ entre a quantidade de energia prescrita e aquela efetivamente recebida por pacientes em UTI ${ }^{9}$. Um recente estudo brasileiro, que avaliou causas de inadequação energética em doentes hospitalizados, observou que a maior discrepância entre a energia prescrita e a recebida pelo paciente ocorre justamente em 
$\mathrm{UTI}^{10}$. Sabe-se também que esta inadequação é ainda pior no doente crítico cirúrgico, quando comparado ao doente internado na UTI por problemas clínicos ${ }^{11}$.

Outro problema em discussão é a via de acesso utilizada para realização da TN. A terapia nutricional enteral (TNE) pode reduzir o hipercatabolismo do doente crítico e manter o trofismo da mucosa intestinal, além de reduzir translocação bacteriana e infecções sistêmicas ${ }^{12}$. Assim, o uso de TNE na UTI parece melhorar o estado nutricional, auxiliar a resposta imunológica e modular a inflamação sistêmica ${ }^{13}$. Ao se comparar com a terapia de nutrição parenteral (TNP), a TNE reduz complicações, tempo de internação e, consequentemente, custos hospitalares ${ }^{14}$.

Recentemente, a associação de TNP com TNE também tem sido motivo de acalorada discussão ${ }^{15}$. A Sociedade Européia de Nutrição Enteral e Parenteral (E.S.P.E.N) propõe a complementariedade de NE com NP, já a partir de 3 dias com NE insuficiente ${ }^{6}$. No entanto, estudo de 2011 apontou que o uso suplementar precoce de NP combinada à NE aumentou o número de novas infecções e o tempo de internação em UTI e hospitalar, ao ser comparada com a suplementação tardia da $\mathrm{NP}^{16}$. Assim, a indicação e administração de TNP devem ser bem avaliadas, visto que seu uso inapropriado poderia piorar desfechos clínicos do doente crítico ${ }^{16}$.

Todavia, muitos médicos intensivistas, não especialistas em nutrição clínica, embora reconheçam a importância clínica da TN em situações críticas sentem-se inseguros ao prescrever $\mathrm{NP}^{9}$. Dentre as causas que podem justificar essa insegurança inclui-se não estar adequadamente 
preparado para prescrever a $\mathrm{TN}^{9,10}$. Lamentavelmente o ensino de nutrição clínica ainda não faz parte da educação formal das escolas médicas na graduação e na pós-graduação ${ }^{11}$.

Nos Estados Unidos, menos de $25 \%$ das escolas médicas apresentam temas de nutrição em seu curriculum e em metade dessas escolas a nutrição é uma disciplina opcional, escolhida por menos de $6 \%$ dos estudantes ${ }^{17}$. Talvez por isso, cada vez menos médicos busquem a nutrição clínica como uma especialidade, ou mesmo um assunto de interesse $^{18}$.

A legislação brasileira, no que diz respeito à $T N$, é muito avançada em relação aos demais países. Desde 1998, a portaria 272 da Agência Nacional de Vigilância Sanitária reforça o papel do médico como coordenador clínico das equipes multiprofissionais de $\mathrm{TN}^{19}$. No entanto, ainda são poucas as escolas médicas brasileiras que incluem o ensino da nutrologia em sua grade curricular. Em relação à pós-graduação, também uma pequena minoria dos cursos médicos do país oferece residência e treinamento pós-graduado clínico em nutrologia. Existe oferta de cursos de extensão universitária e pós-graduação do tipo latu senso em TN, mas a frequência de médicos nestes cursos não supera $15 \%$ das vagas oferecidas.

A implantação de protocolos de conduta em TN na UTI pode ser uma alternativa relevante para melhorar seus resultados. A adoção de protocolos clínicos consegue melhorar a adequação nutricional em cerca de $10 \%{ }^{20}$, 
porém, mesmo nos locais em que se utilizam protocolos, a TN pode permanecer mal conduzida ${ }^{21}$.

Os maus resultados podem estar associados ao desconhecimento de médicos intensivistas sobre temas referentes à $T N$ e sua resistência a novas orientações relacionadas aos cuidados com seus pacientes. Um estudo mostrou que apenas $40 \%$ dos intensivistas acataram as orientações dadas pela equipe multidisciplinar de $\mathrm{TN}^{22}$. Em outro estudo, a implantação de um protocolo de conduta nutricional, dirigido por enfermeiras em hospital universitário, conseguiu aumentar a adequação energética de $52 \%$ para $68 \%{ }^{23}$. Todavia, quando os médicos se recusaram a acatar o referido protocolo, a adequação foi de $55 \%$, valor semelhante ao inicial ${ }^{23}$. Os autores reforçam que a relutância dos médicos ao utilizar o protocolo nutricional limitou sua eficácia e que, para aumentar sua adesão, seria necessário o desenvolvimento de projetos educacionais ${ }^{23}$.

Educar o médico atuante em UTI pode ser fundamental para melhorar a qualidade da TN. Assim sendo, existe a necessidade de se criar novos modelos de educação médica em TN. A existência de cursos e congressos sobre esse tema pouco logrou para modificar seu panorama na prática clínica em doentes críticos. Isso pode ter ocorrido frente à existência cada vez maior de novos temas em terapia intensiva que competem por atenção médica e à carga de trabalho excessiva sobre o médico intensivista, que nem sempre pode frequentar cursos de atualização.

Há mais de 40 anos, a necessidade de mudar a educação médica no Brasil vem sendo discutida em foros diversos ${ }^{24,25}$. Desde sua criação, em 
1962, a Associação Brasileira de Educação Médica (Abem) questiona e propõe modificações no complexo formador de médicos. Mais recentemente, a Comissão Interinstitucional Nacional de Avaliação do Ensino Médico (Cinaem) avaliou as escolas médicas e formulou diagnósticos sombrios e extremamente preocupantes ${ }^{26}$. As deficiências apontadas incluem a dissociação entre teoria e prática e a presença de currículos arcaicos ${ }^{24}$.

O currículo médico tradicional foi proposto na década de 20 pela comissão Flexner, nos Estados Unidos, após cumprir a verificação de quais escolas médicas atuantes naquele país poderiam continuar seus trabalhos. Com base em suas observações, a comissão propôs que o currículo médico deveria constar de alguns anos de aprendizado de ciências ditas básicas da medicina e de formação clínica e que as escolas deveriam dispor de um hospital para estágio dos alunos. Daquela época em diante modificações extremamente importantes ocorreram na medicina, com poucas alterações na estrutura do currículo médico ${ }^{27}$.

$\mathrm{Na}$ tentativa de mudança do modelo de educação médica surgiu o método PBL (Problem Based Learning - Aprendizado Baseado em Problemas). O referido método propõe que o aluno aprenda através de casos e pesquisas, em substituição à estrutura convencional de aulas. Outro conceito que surgiu com o intuito de melhorar a qualidade do conhecimento médico foi o modelo de educação continuada in loco. Esse modelo propõe atualizar e educar continuamente o médico em sua rotina diária, através da discussão de casos clínicos ${ }^{28}$. 
No sentido de contribuir para o aprimoramento do modelo de educação médica, julgamos oportuno avaliar o modelo de educação em serviço para modificar o padrão de condutas relacionadas à TN de médicos intensivistas. Nossa hipótese compreende que o treinamento em serviço, baseado em um programa de educação médica em terapia nutricional alicerçado em protocolos e diretrizes, estabelecidos à luz de evidências científicas, seria capaz de modificar favoravelmente a abordagem médica nutricional do paciente crítico. 


\subsection{Justificativa do ESTUdO}

Em pacientes sob cuidados intensivos, a qualidade da terapia nutricional mostra-se muitas vezes longe do que se considera ideal apesar das evidências consistentes sobre seus benefícios.

A introdução de um programa de educação médica em TN utilizando protocolos de conduta e discussões à beira leito em UTI poderia unificar condutas e orientar ações, visando incremento da qualidade da TN utilizada, e também, possivelmente, melhorar a evolução clínica de pacientes críticos. 
Objetivo 


\section{OBJETIVO}

Avaliar a influência da introdução de um novo modelo de educação médica em terapia nutricional em unidade de terapia intensiva sobre a qualidade da terapia nutricional e o desfecho clínico de seus pacientes. 
Métodos 


\section{MÉTODOS}

\subsection{Desenho do ESTUdo}

Estudo de intervenção, prospectivo, aberto e com controle não simultâneo, com proposta de obter dados indicativos de qualidade da TN oferecida a pacientes internados em UTI antes e após a introdução de um programa educacional em TN, assim como seu impacto no desfecho clínico destes pacientes.

\subsection{LOCAL DE DESENVOLVIMENTO DO ESTUDO}

Unidade de Terapia Intensiva Cirúrgica e Laboratório de Investigação Médica (LIM) 35 do Serviço de Cirurgia do Aparelho Digestivo do Instituto Central do Hospital das Clínicas da Faculdade de Medicina da Universidade de São Paulo (HC-FMUSP), São Paulo, Brasil. 


\subsection{COMISSÃO dE ÉTICA}

O plano de pesquisa foi submetido e aprovado pela Comissão ÉticoCientífica do Departamento de Gastroenterologia da Faculdade de Medicina da Universidade de São Paulo (FMUSP), em 16 de outubro de 2008 (Anexo A); e pela Comissão de Ética para Análise de Projetos de Pesquisa do Hospital das Clínicas do HC-FMUSP (CAPPesq), em 16 de Dezembro de 2009 (Anexo B). Todos os pacientes ou seus representantes legais assinaram o Termo de Consentimento Livre e Esclarecido (Anexo C).

\subsection{Estimativa do Tamanho da Amostra}

O tamanho da amostra do presente estudo foi calculado com base no estudo de Minard e cols ${ }^{29}$. Os autores estudaram em 27 pacientes críticos os resultados da aplicação de um protocolo nutricional, visando redução de tempo de jejum na UTI. Observaram redução no tempo de permanência em UTI (18,5 $\pm 8,8$ dias $\times 11,3 \pm 6,1$ dias) no grupo de pacientes que utilizou NE precoce $(n=12)$, quando comparado ao grupo de doentes que receberam dieta mais tardiamente $(n=15)^{29}$. Com base nas observações desses autores, calculou-se um tamanho de amostra mínimo de 32 pacientes para compor cada grupo avaliado no presente estudo. Considerou-se a aplicação de teste t de Student para comparação entre as médias de dias de permanência na UTI dos grupos pré e pós- programa educacional, supondo uma distribuição normal para o tempo de permanência na UTI, a um nível de significância de $5 \%$ e poder de teste de $95 \%$. 


\subsection{Pacientes}

Foram selecionados 100 pacientes ( $1^{\underline{a}}$ fase $n=50,2^{a}$ fase $n=50$ ) internados entre Dezembro de 2009 e Dezembro de 2010 na Unidade de Terapia Intensiva Cirúrgica do Serviço de Cirurgia do Aparelho Digestivo (HC-FMUSP). Foram incluídos no estudo pacientes de ambos os sexos com idade entre 18 e 80 anos, tempo de admissão na UTI menor que 2 dias, tempo de permanência na UTI maior que 5 dias e assinatura obrigatória por ele ou seu representante legal do termo de consentimento livre e esclarecido (Anexo C).

\subsection{Protocolo de estudo}

O protocolo do presente estudo foi conduzido em três diferentes fases:

\subsubsection{FASE 1 - PRÉ-PROGRAMA EDUCACIONAL EM TN (PP)}

Nesta fase, 50 pacientes adultos recém-admitidos na UTI foram selecionados consecutivamente para avaliação diária, por nutricionista treinado, sem interferência no tratamento. A prática da TN foi avaliada nesses pacientes, para verificar sua conformidade com a Diretriz Canadense de Terapia Nutricional para o doente crítico ${ }^{3}$ e diagnosticar os principais problemas na gestão da TN. Sua análise ocorreu pela aplicação de indicadores de qualidade de TN previamente descritos ${ }^{30}$ (Quadro 1) e 
pelo registro de complicações relacionadas à TN (Quadro 2), por meio de consulta diária ao prontuário do paciente na UTI.

A necessidade energética e proteica de cada paciente foi estimada segundo a regra de bolso recomendada pelas sociedades americana (A.S.P.E.N) e europeia (E.S.P.E.N) para o doente crítico ${ }^{6,8}$, que preconiza a administração de $25 \mathrm{Kcal} / \mathrm{Kg}$ e $1,5 \mathrm{~g} / \mathrm{Kg}$ de proteína por dia. Para a estimativa das necessidades energética e proteica utilizou-se preferencialmente o peso corpóreo atual de cada paciente. $\mathrm{Na}$ ausência deste dado em seu prontuário, utilizou-se o peso corpóreo habitual referido pelo paciente ou seu representante.

Dados descritivos, clínicos e nutricionais (Quadros 3 e 4) dos pacientes, foram anotados em formulários individuais específicos (Anexos D, E e F), desde sua inclusão até a alta na UTI ou óbito. Essas informações foram armazenadas em banco informatizado, em forma de planilha no programa Microsoft $\circledast$ Excelß 2003, por meio de processo de dupla digitação, para minimizar o risco de erro. 
Quadro 1 - Relação dos indicadores de qualidade de terapia nutricional aplicados no presente estudo ${ }^{30}$

\begin{tabular}{|c|c|}
\hline Indicador & Meta \\
\hline $\begin{array}{l}\text { Tempo para } \\
\text { início da } \\
\text { terapia } \\
\text { nutricional }\end{array}$ & $\begin{array}{l}\text { Mensurar a frequência de doentes com tempo de jejum } \\
\text { inadequado (>48 horas) antes do início da terapia } \\
\text { nutricional. }\end{array}$ \\
\hline $\begin{array}{l}\text { Porcentagem } \\
\text { da meta } \\
\text { energética } \\
\text { atingida }\end{array}$ & $\begin{array}{l}\text { Mensurar a frequência de pacientes que receberam } \\
\text { aporte energético inadequado, acima ou abaixo das } \\
\text { necessidades energéticas estimadas em relação ao total } \\
\text { de pacientes em terapia nutricional. Utilizou-se o peso } \\
\text { habitual referido pelo paciente ou seu representante. }\end{array}$ \\
\hline $\begin{array}{l}\text { Energia } \\
\text { prescrita vs } \\
\text { recebida }\end{array}$ & $\begin{array}{l}\text { Mensurar a frequência de pacientes que receberam oferta } \\
\text { energética acima ou abaixo da quantidade prescrita em } \\
\text { relação ao total de pacientes em terapia nutricional. }\end{array}$ \\
\hline $\begin{array}{l}\text { Quantidade } \\
\text { máxima } \\
\text { energética } \\
\text { recebida }\end{array}$ & $\begin{array}{l}\text { Anotar o valor máximo de energia recebida pelo paciente } \\
\text { durante qualquer dia ao longo da internação na unidade } \\
\text { de terapia intensiva. }\end{array}$ \\
\hline $\begin{array}{l}\text { Tempo de } \\
\text { jejum (dias) }\end{array}$ & $\begin{array}{l}\text { Verificar a interrupção da terapia nutricional por mais de } \\
24 \text { horas. }\end{array}$ \\
\hline $\begin{array}{l}\text { Tipo de terapia } \\
\text { nutricional } \\
\text { utilizada }\end{array}$ & $\begin{array}{l}\text { Quantificar o número de pacientes que receberam } \\
\text { nutrição enteral, nutrição parenteral ou a combinação } \\
\text { entre elas durante a internação na unidade de terapia } \\
\text { intensiva. }\end{array}$ \\
\hline
\end{tabular}


Quadro 2 - Relação das complicações relacionadas à terapia nutricional avaliadas no presente estudo.

\begin{tabular}{|c|c|}
\hline Complicação & Parâmetro \\
\hline $\begin{array}{l}\text { Volume de } \\
\text { resíduo gástrico }\end{array}$ & $\begin{array}{l}\text { Qualquer valor superior a } 250 \mathrm{ml} \text {, por ocasião da } \\
\text { aspiração gástrica }^{3} \text {. }\end{array}$ \\
\hline Vômitos & Ocorrência de pelo menos um episódio em $24 \mathrm{~h}$. \\
\hline Diarreia & $\begin{array}{l}\text { Ocorrência de três ou mais evacuações líquidas, em } \\
\text { grande quantidade, em } 24 h^{31} \text {. }\end{array}$ \\
\hline Hiperglicemia & Aferição de glicemia capilar $\geq 180 \mathrm{mg} / \mathrm{dl}^{32}$. \\
\hline Hipoglicemia & Aferição de glicemia capilar $\leq 70 \mathrm{mg} / \mathrm{dl}$. \\
\hline $\begin{array}{l}\text { Distensão } \\
\text { abdominal }\end{array}$ & $\begin{array}{l}\text { Diagnosticada por exame físico, conforme relatado em } \\
\text { prontuário do paciente. }\end{array}$ \\
\hline $\begin{array}{l}\text { Complicação } \\
\text { mecânica }\end{array}$ & Obstrução ou saída inadvertida de acesso enteral. \\
\hline $\begin{array}{l}\text { Infecção de } \\
\text { cateter venoso } \\
\text { utilizado para } \\
\text { nutrição } \\
\text { parenteral }\end{array}$ & $\begin{array}{l}\text { Presença de um dos seguintes achados clínicos: febre, } \\
\text { dor, calor ou eritema no sítio vascular envolvido associado } \\
\text { a culturas de ponta de cateter pelo método semi- } \\
\text { quantitativo mais } 15 \text { unidades formadoras de colonias e } \\
\text { hemocultura negativa ou não realizada. }{ }^{33}\end{array}$ \\
\hline
\end{tabular}


Quadro 3 - Relação dos dados descritivos e clínicos coletados no presente estudo.

Idade em anos

Sexo

Sistema de classificação de gravidade de APACHE II (Acute Physiology and Chronic Health Evaluation II) ${ }^{34}$

Diagnóstico principal de admissão na UTI

Diagnósticos secundários de admissão e acompanhamento na UTI

Data de internação hospitalar

Data da intervenção cirúrgica e da nova intervenção (se aplicável)

Data de admissão na UTI

Data de inclusão no estudo

Data de início da TN

Data da saída da UTI

Motivo de saída da UTI (alta / óbito) 
Quadro 4 - Relação dos dados nutricionais coletados no presente estudo.

Peso corpóreo habitual há 6 meses $(\mathrm{PH})$ expresso em quilogramas e informado pelo paciente ou seu acompanhante.

Peso corpóreo na admissão hospitalar (PA) expresso em quilogramas e obtido do prontuário do paciente.

Porcentagem de perda de peso corpóreo (\%PP), assim calculada ${ }^{35}: \% \mathrm{PP}=$ (PH - PA) / PH x 100\%.

Estatura corpórea em metros, informada pelo paciente ou seu acompanhante. Índice de Massa Corporal (IMC) ${ }^{36}$ expresso em quilogramas por metro quadrado, assim calculado: IMC $=\mathrm{PA}$ ou $\mathrm{PH} / \mathrm{A}^{2}$.

Avaliação Subjetiva Global ${ }^{37}$ (Anexo G), aplicada pelo nutricionista no paciente ou seu representante e expressa em diferentes graus (A-Eutrófico, B- Desnutrido leve a moderado e C- Desnutrido grave).

\subsubsection{Fase 2- Programa Educacional eM TN (PE)}

Esta fase foi composta por quatro etapas distintas, a saber:

- Etapa 1 - Avaliação do conhecimento existente dos médicos intensivistas sobre nutrição clínica - teste pré-PE: os médicos com atividade clínica na UTI, onde foi realizado o presente estudo (17 médicos, incluindo residentes), foram convidados a preencher um questionário com dez questões de múltipla escolha referentes a temas do dia a dia em nutrição clínica, que incluíram perguntas sobre 
vias de acessos para TN, NE precoce, indicações de NP, tempo de jejum e complicações da TN (Anexo H).

- Etapa 2 - Desenvolvimento de protocolos específicos: de acordo com os dados obtidos na primeira fase e orientado pelas Diretrizes Canadenses para TN, ${ }^{3}$ foram desenvolvidos cinco protocolos de conduta sobre TN, direcionados para os principais problemas encontrados na fase 1, a saber: via de acesso para TN, manejo da terapia de NE, indicação da terapia de NP, controle de diarreia e de estase gástrica (Anexo I).

- Etapa 3 - Educação e formação em serviço: ao longo de dois meses consecutivos, foi realizado um programa diário de treinamento da equipe médica na UTI (diaristas, plantonistas e residentes), para estabelecer e implantar os protocolos de condutas nutricionais. $\mathrm{O}$ programa de educação incluiu palestras sobre os principais tópicos em nutrição clínica (avaliação nutricional e planejamento da TN, indicação de terapia enteral e parenteral, monitoramento e efeitos adversos, indicadores de controle de qualidade e benefícios esperados da implantação de protocolos clínicos de nutrição). A seguir, os protocolos foram apresentados aos médicos, que receberam orientação quanto à sua utilização, principalmente por meio de discussão de casos à beira leito. 
- Etapa 4 - Reavaliação do conhecimento nutricional após o programa de educação - teste pós-PE: após o treinamento de condutas nutricionais, os médicos intensivistas foram convidados a preencher novamente o mesmo teste de múltipla escolha (Anexo $\mathrm{H}$ ). Os resultados dos pré e pós- testes foram comparados estatisticamente.

\subsubsection{FASE 3 Pós- PROGRAMA EDUCACIONAL EM TN (PO)}

Um mês após a conclusão da fase 2, uma segunda coorte de 50 pacientes consecutivos foi avaliada observando-se as mesmas variáveis e aplicando-se os mesmos métodos descritos na fase 1. Os dados da TN e os dados descritivos, clínicos e nutricionais dos pacientes coletados nesta fase foram comparados estatisticamente com aqueles coletados na fase 1, préprograma educacional (PP).

\subsection{ANÁlise eStatística dos dados}

Estatísticas descritivas de frequências absolutas (n) e relativas (\%) foram apresentadas para as medidas qualitativas. Estatísticas sumárias de tendência central (média e mediana); dispersão e posição (desvio padrão DP, percentil 25 - Per25; percentil 75 - Per75; mínimo - min e máximo máx) foram apresentadas para as medidas quantitativas.

Teste qui-quadrado de Pearson ou exato de Fisher foram aplicados para avaliar a associação entre duas medidas qualitativas. Para a comparação de medidas quantitativas entre os dois grupos de pacientes (fases 1 e 2) foi aplicado teste t de Student ou, quando a distribuição normal 
da variável foi rejeitada, teste não paramétrico de Mann-Whitney. Para a comparação de dias de internação hospitalar e dias de UTI entre as categorias das medidas qualitativas de interesse foram aplicados testes não paramétricos de Mann-Whitney (para duas categorias de respostas) ou de Kruskal-Wallis (para mais de duas categorias de respostas). A relação entre dias de internação hospitalar e dias em UTI com medidas quantitativas foi avaliada pelo método de correlação de Spearman. Quando existiu correlação significativa entre duas medidas, ou seja, quando o coeficiente de correlação (r) foi significativamente diferente de zero, seu grau foi avaliado. Valores absolutos de $r=|r|$ menores que 0,4 foram considerados de fraca correlação; quando $0,4 \leq|r|<0,7$ a correlação foi considerada moderada; quando $|r| \geq 0,7$ a correlação foi considerada forte entre as duas medidas observadas. Coeficientes negativos significaram que o aumento de uma medida implicou no decréscimo da outra, enquanto coeficientes positivos significaram que o aumento de uma medida implicou no aumento da outra.

Os fatores e co-variáveis de efeito nos dias de permanência na UTI também foram avaliados por modelo linear generalizado de quaseverossimilhança com variância $=$ média $^{2}$ e função de ligação logarítmica.

Diferenças foram consideradas significativas quando o nível descritivo do teste (valor de $\mathrm{p}$ ) foi menor que 0,05 . 
Resultados 


\section{RESULTADOS}

No presente estudo os resultados são descritos em etapas que compreendem: resultados da avaliação de conhecimentos em TN por médicos intensivistas, antes e após a implantação de programa de educação em TN; comparação das características demográficas dos grupos de pacientes avaliados antes e após a intervenção educacional; resultados relacionados à qualidade da $\mathrm{TN}$ realizada antes e após a intervenção nutricional e finalmente resultados relacionados ao desfecho clínico dos pacientes antes e após a intervenção nutricional.

\subsection{CONHECIMENTOS EM TN POR MÉDICOS INTENSIVISTAS}

Em avaliações realizadas com 17 médicos da UTI (diaristas, plantonistas e residentes) foram observadas maiores notas no teste de conhecimentos em TN após a implantação de programa de educação em TN, como se observa na Figura 1. 


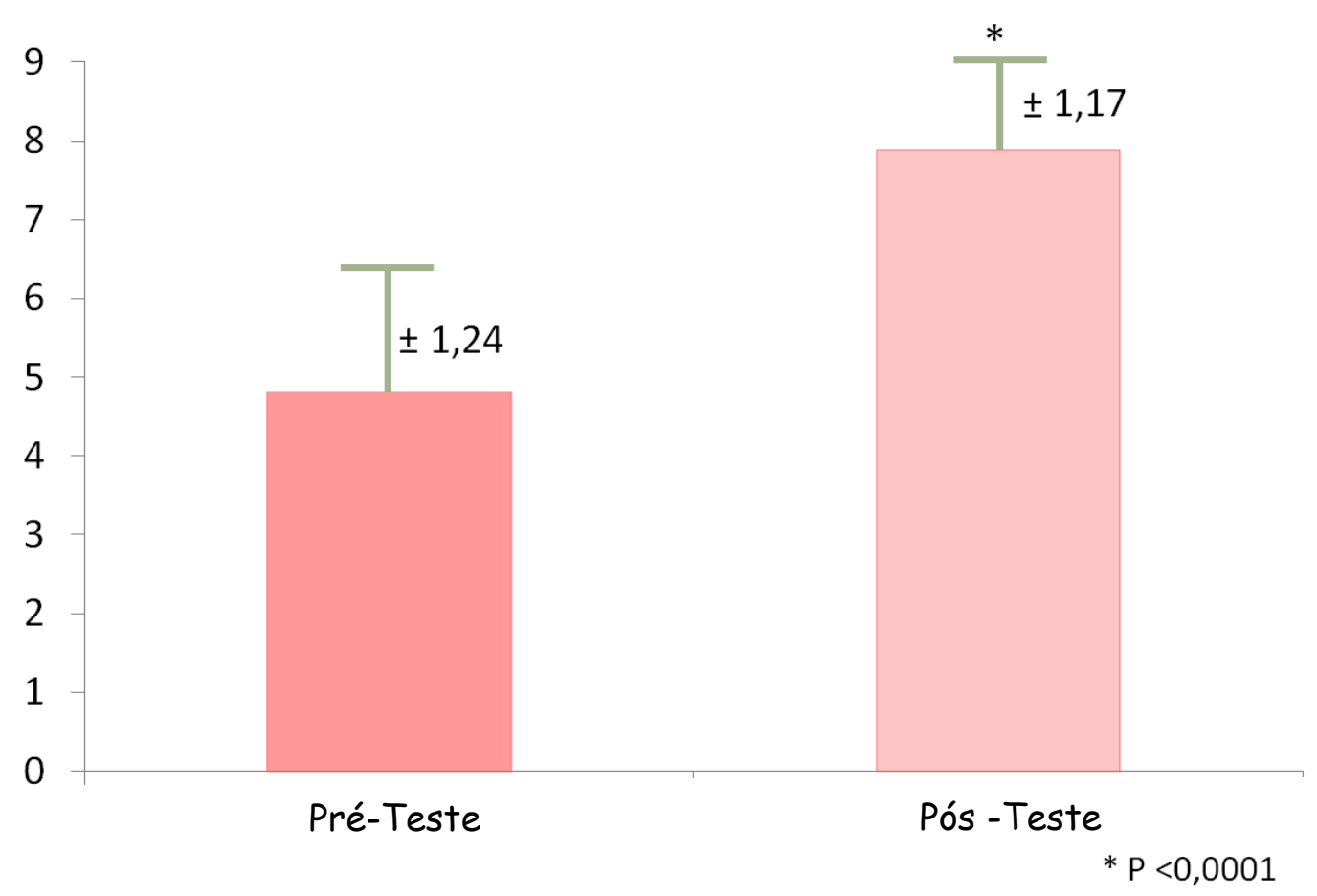

Figura 1 - Comparação dos acertos obtidos na avaliação de conhecimentos em terapia nutricional aplicada a médicos intensivistas antes (pré-teste) e após o desenvolvimento de programa educacional de terapia nutricional (pós-teste). Dados apresentados em média e desvio padrão de acertos.

\subsection{Características demográficas dos Pacientes}

As características dos grupos de pacientes pré-programa educacional (PP) e pós-programa educacional (PO) não diferiram entre si em relação ao sexo, idade, ASG, APACHEIl, tipo de diagnóstico na admissão (clínico vs cirúrgicos) e porcentagem de perda de peso. O IMC foi maior nos pacientes do grupo PO, quando comparado ao grupo PP, como se observa na Tabela 1. 
Tabela 1 - Comparação das características demográficas entre os grupos de pacientes estudados pré-programa educacional (PP) e pós-programa educacional (PO)

\begin{tabular}{|c|c|c|c|}
\hline Variável & PP & PO & Valor de $P$ \\
\hline Masculino, $\mathrm{n}^{\mathrm{a}}$ & 37 & 33 & 0,383 \\
\hline Idade em anos ${ }^{b}$ & $62,3(15,0)$ & $57,4(14,2)$ & 0,098 \\
\hline $\mathrm{IMC}$ em kg/m²b & $24(4,6)$ & $26,1(5,5)$ & 0,042 \\
\hline APACHE $\|^{b}$ & $21,7(7,4)$ & $20,8(4,5)$ & 0,466 \\
\hline$\%$ Perda de Peso em $\mathrm{Kg}^{\mathrm{c}}$ & $7(0-12,7)$ & $4(1,1-7,9)$ & 0,305 \\
\hline Grau de Avaliação Subjetiva Global & $\mathrm{B}$ & B & - \\
\hline \multicolumn{4}{|l|}{ Tipo de Admissão } \\
\hline Admissões Cirúrgicas $^{c}$ & $38(76)$ & $29(58)$ & 0,056 \\
\hline Admissões Clínicas ${ }^{c}$ & $12(24)$ & $21(42)$ & \\
\hline \multicolumn{4}{|l|}{ Diagnóstico Principal } \\
\hline Acidente Vascular Cerebral $^{d}$ & $4(8)$ & $6(12)$ & 0,762 \\
\hline Complicações Clínicas ${ }^{d}$ & $6(12)$ & $13(26)$ & \\
\hline Câncer Não Cirúrgico ${ }^{d}$ & $2(4)$ & $2(4)$ & \\
\hline Gastrocirurgia $^{d}$ & $14(28)$ & $10(20)$ & \\
\hline Cirurgia Vascular ${ }^{d}$ & $8(16)$ & $6(12)$ & \\
\hline Cirurgia Urológica $^{d}$ & $3(6)$ & $2(4)$ & \\
\hline Cirurgia Oncológica ${ }^{d}$ & $5(10)$ & $3(6)$ & \\
\hline Complicações Cirúrgicas $^{d}$ & $5(10)$ & $6(12)$ & \\
\hline Trauma $^{d}$ & $3(6)$ & $2(4)$ & \\
\hline
\end{tabular}




\subsection{QUALIDADE DA TERAPIA NUTRICIONAL}

A comparação dos resultados observados após a aplicação do programa educacional em $\mathrm{TN}$, em relação àqueles obtidos antes da aplicação do programa, revelou: menor tempo de jejum, maior quantidade máxima de energia administrada, maior porcentagem atingida da necessidade energética estimada (Tabela 2 e figuras 2, 3 e 4, respectivamente) e maior número proporcional de pacientes $(60 \%$ vs $26 \%$, $\mathrm{p}<0,001)$ que utilizaram NE precoce ( $<48$ horas da admissão na UTI). A indicação de nutrição enteral precoce não foi diferente entre os que receberam o tratamento clínico ou cirúrgico $(p$ 0,423) . 
Tabela 2 - Resultados da comparação de variáveis de qualidade da terapia nutricional obtidas nos grupos pré-programa educacional (PP) e pósprograma educacional (PO) no que se refere a complicações da TN e indicadores de qualidade da terapia nutricional.

PP

PO Valor de $P$

\section{Complicações da TN}

$\begin{array}{lccc}\text { Vômitos }^{\text {a }} & 05(10,2) & 05(10) & 0,973 \\ \text { Diarreia }^{\text {a }} & 09(18,4) & 04(8) & 0,127 \\ \text { Estase gástrica }^{\mathrm{b}} & 07(14,3) & 02(4) & 0,092 \\ \text { Hiperglicemia }^{\mathrm{a}} & 31(63,3) & 24(48) & 0,126\end{array}$

Indicadores de Qualidade em TN

Jejum $<48$ horas $^{a}$

$12(24)$

$30(60)$

$<0,001$

Dias de jejum ${ }^{c}$

$3,0(2-6)$

$1,0(0-4)$

0,002

Energia máxima

$1220(920-1600)$

$1800(1600-1904)<0,001$

administrada $(\mathrm{Kcal})^{\mathrm{c}}$

Adequação

$77,3(51,7-92,4)$

$98,8(83,8-107,3)$

$<0,001$

Energética $(\mathrm{kcal})^{\mathrm{c}}$

aDados apresentados como número de ocorrências (\%), Teste de Pearson Qui-quadrado. ${ }^{b}$ Dados apresentados como número (\%), teste exato de Fisher. ${ }^{\circ}$ Dados apresentados em mediana (intervalo interquartil), teste de Mann-Whitney. 


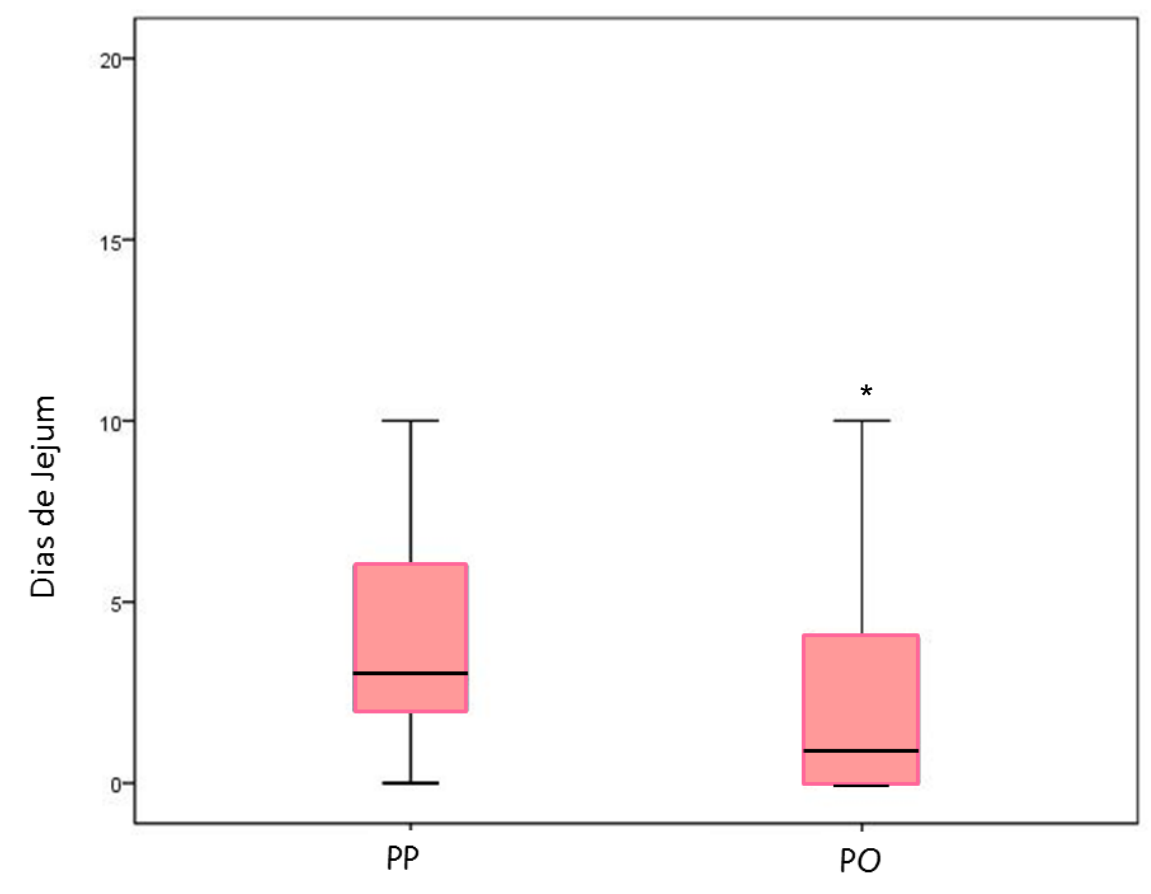

Figura 2 - Representação gráfica dos dias em jejum (mediana) durante a terapia nutricional entre os pacientes dos grupos pré-programa educacional (PP) e pós-programa educacional (PO). Teste de Mann-Whitney, ${ }^{*} \mathrm{p}=0,002$ (PP vs PO) 


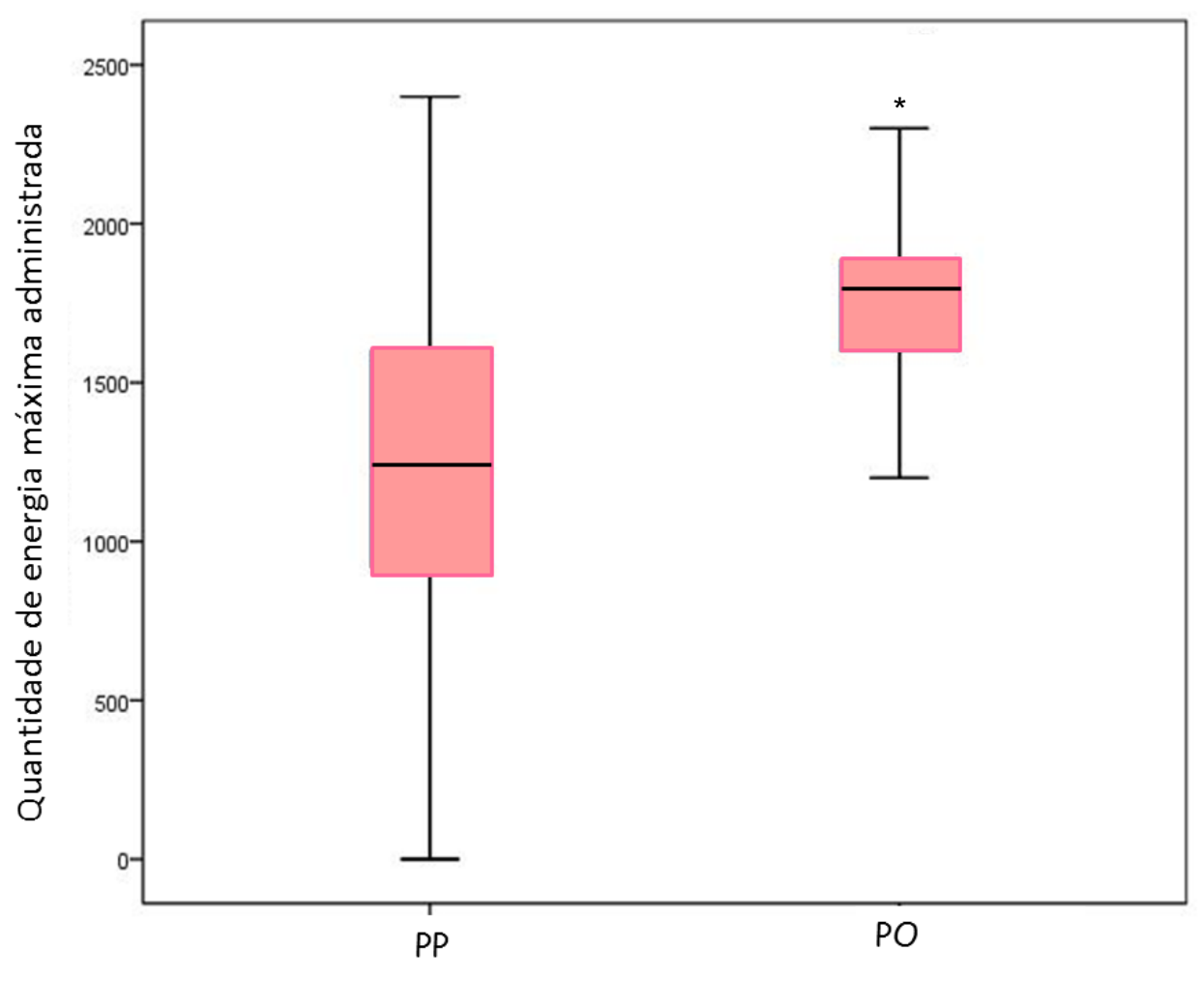

Figura 3 - Representação gráfica da comparação da quantidade de energia máxima administrada entre os pacientes dos grupos pré-programa educacional (PP) e pós-programa educacional (PO). Teste de MannWhitney, ${ }^{*} \mathrm{p}=0,001$ (PP vs PO) 


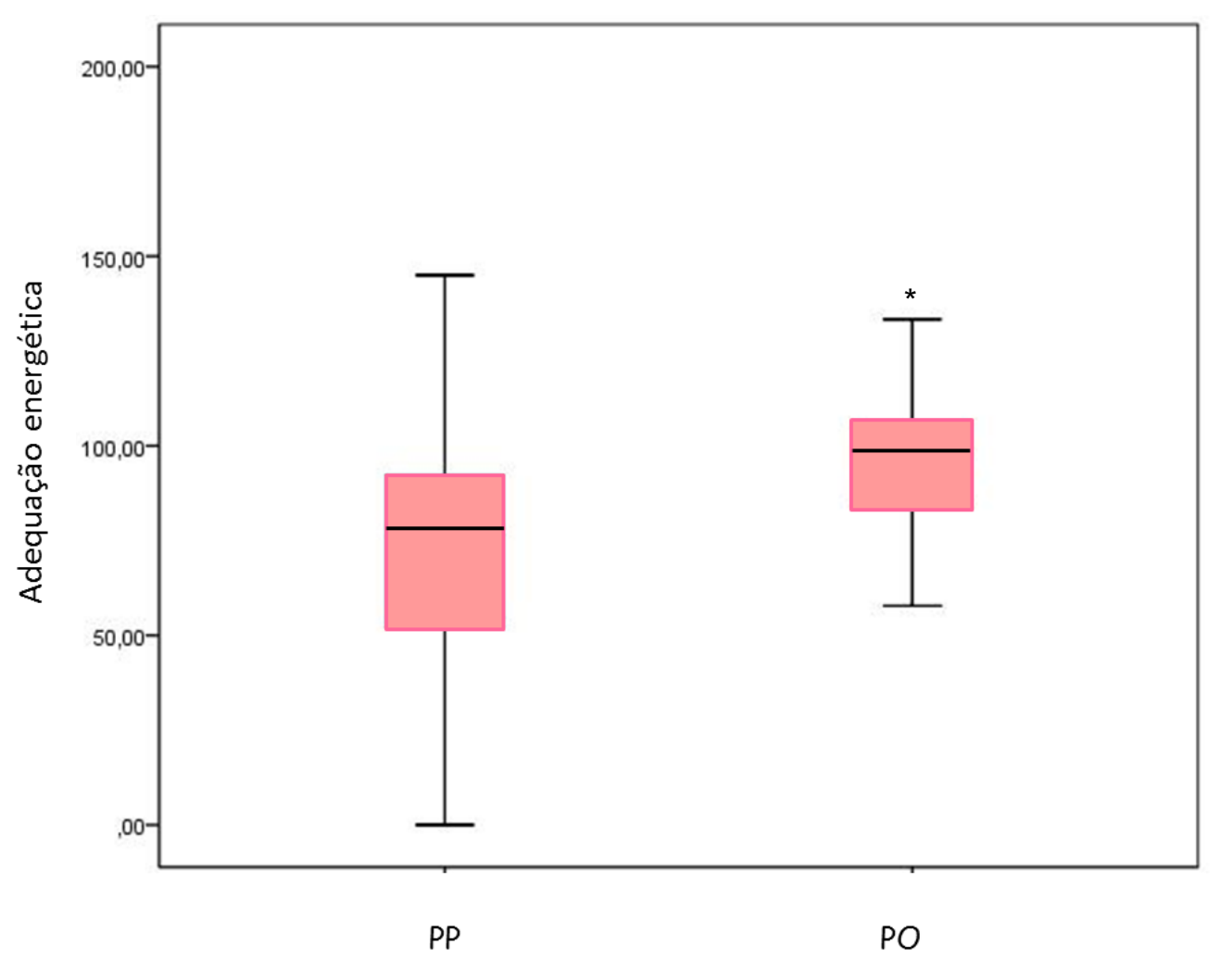

Figura 4 - Representação gráfica da comparação da adequação energética (quantidade recebida de energia em relação à necessidade energética estimada) entre os pacientes dos grupos pré-programa educacional (PP) e pós-programa educacional (PO). Teste de Mann-Whitney, ${ }^{*} \mathrm{p}=0,001$ (PP vs $\mathrm{PO})$ 
Após a aplicação do programa educacional em TN observou-se ainda, em relação aos dados obtidos antes do programa, mudança percentual na via de acesso escolhida para realização de TN, com maior utilização da via enteral $(66,0 \%$ vs $42,5 \%)$ e menor uso de TN parenteral exclusiva $(32,5 \%-24,0 \%)$ e de terapia combinada enteral e parenteral $(25,0 \%-10,0 \%), p<0,05$, conforme mostra a Figura 5.

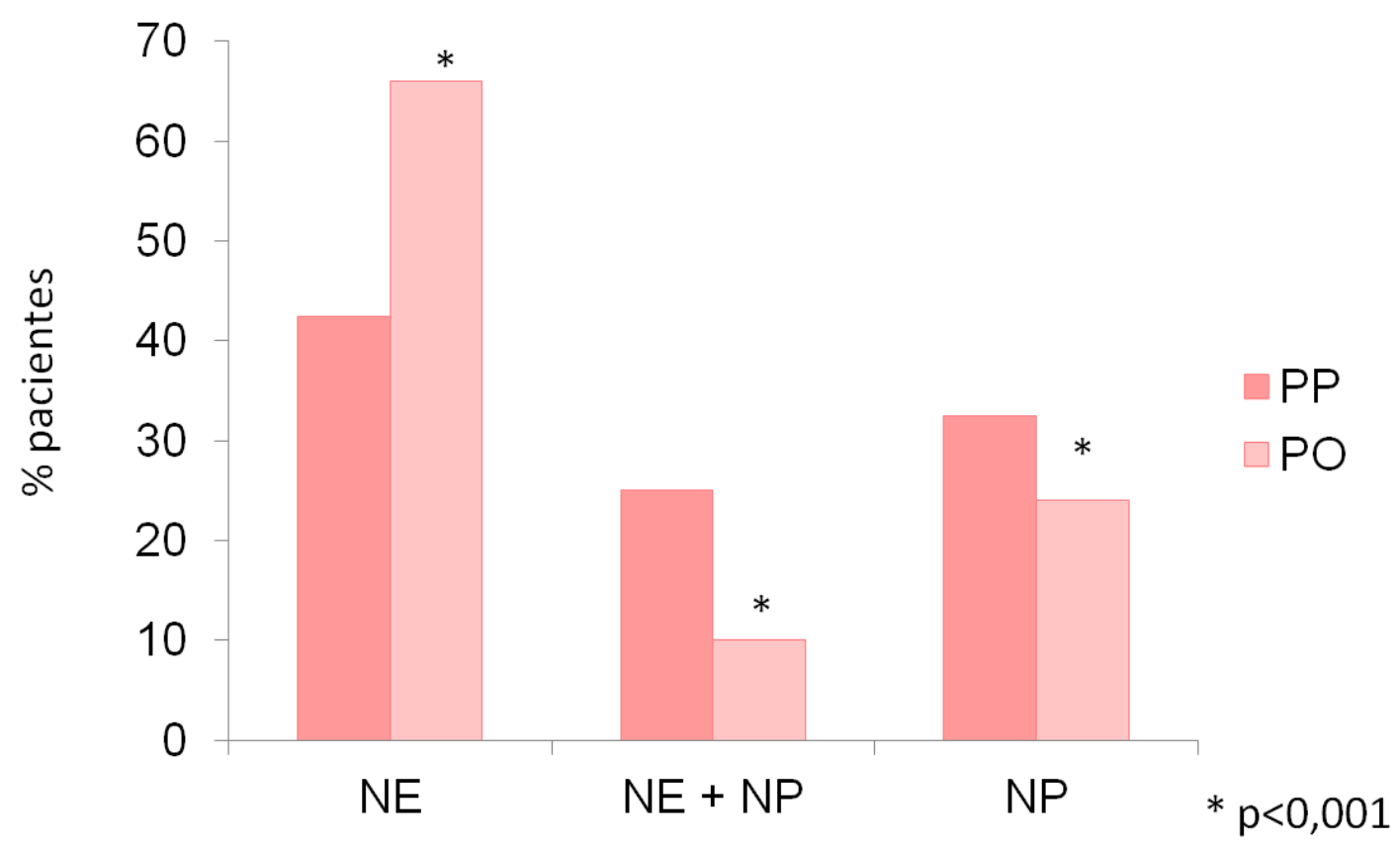

Figura 5 - Comparação da via de acesso para terapia nutricional entre os pacientes dos grupos pré-programa educacional (PP) e pós-programa educacional (PO), avaliados por teste qui-quadrado de Pearson

Legenda: NE: nutrição enteral; NE+NP: combinação de nutrição enteral e nutrição parenteral; NP: nutrição parenteral. 


\subsection{Desfechos CLínICOS}

Após a aplicação do programa educacional em TN observou-se, em relação aos dados obtidos antes do programa, menor tempo de permanência na UTI [PP: 18,5 dias $(12,8-24,3)$ vs PO: 9,5 dias (7-16), $p<0,001]$, conforme mostra a Figura 6.

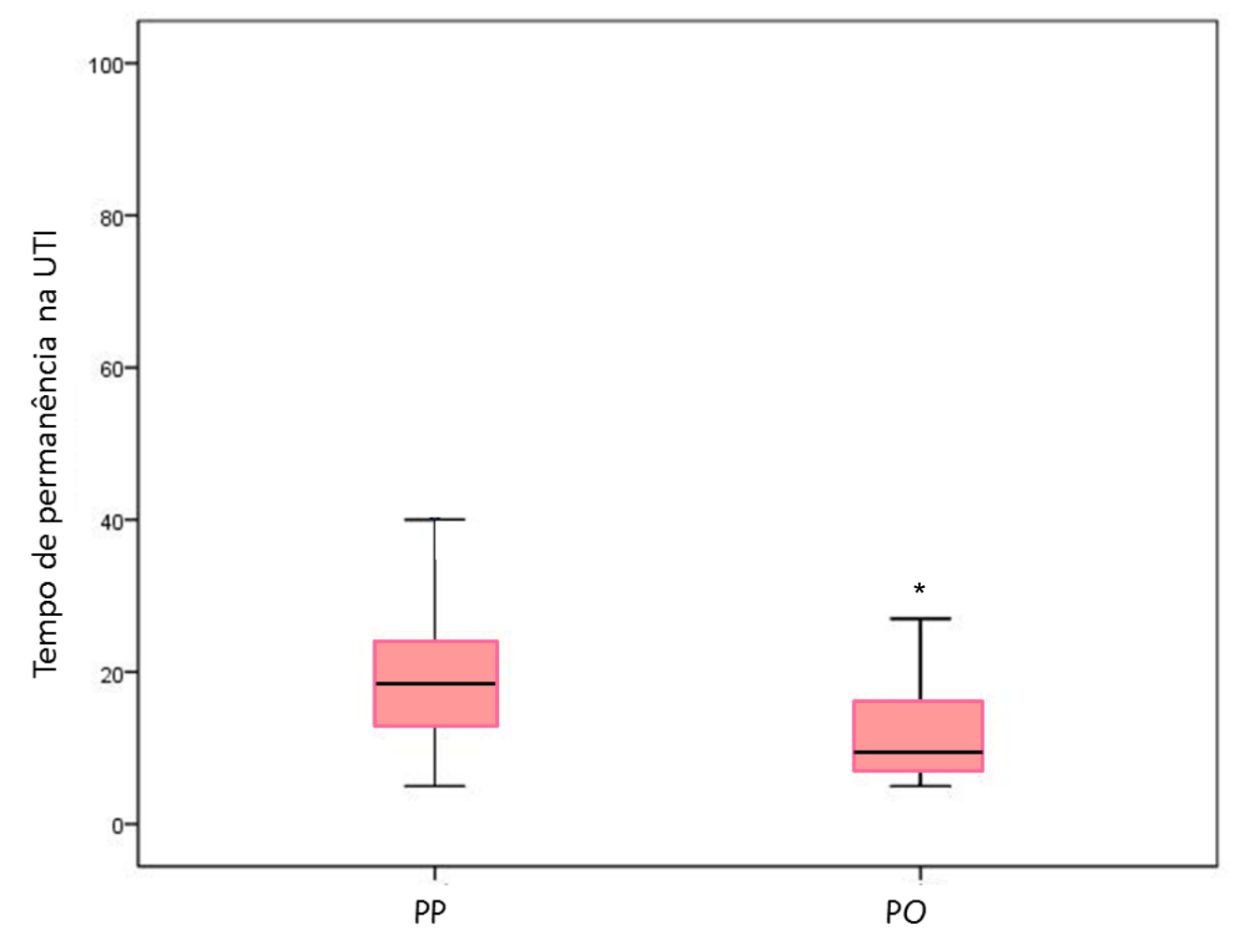

Figura 6 - Representação gráfica da comparação dos dias de permanência na UTI entre os pacientes dos grupos pré-programa educacional (PP) e pósprograma educacional (PO). Teste de Mann-Whitney, ${ }^{*} \mathrm{p}=0,001$ (PP vs PO)

Para os 100 doentes, tomados em conjunto, a permanência na UTI foi significativamente maior, em média, nos pacientes com estase gástrica em relação aos enfermos que não apresentaram estase gástrica (22 dias vs $12,5$ dias $p=0,013)$. Também para os 100 enfermos, o tempo de permanência (dias) na UTI apresentou correlação negativa com quantidade 
de energia máxima administrada $(p=0,012 ; r=-0.25)$ e porcentagem $d a$ necessidade energética atingida $(p=0,002 ; r=-0,303)$, mas não foi correlacionado com admissão por doença de tratamento clínico ou cirúrgico $(p=0,74)$. A análise do modelo linear generalizado de quase-verossimilhança não identificou fator com maior significado sobre o tempo de permanência em UTI entre aqueles que influenciaram esse desfecho clínico (estase gástrica, adequação energética e quantidade máxima de energia administrada), somente o efeito global do programa educacional mantevese significativo.

Tabela 3 - Aplicação de modelo de quase-verossimilhança para tempo de permanência em UTI (dias)

$\begin{array}{lcccc}\text { Efeito } & \text { Estimativa } & \text { E.P. } & \text { t-valor } & \text { p-valor } \\ \text { Intercepto } & 3,718 & 0,575 & 6,470 & \mathbf{0 , 0 0 0 1} \\ \text { Calorias Máximas Administradas } & 0,000 & 0,000 & 0,649 & 0,5178 \\ \text { Adequação Calórica } & -0,004 & 0,003 & -1,246 & 0,2158 \\ \text { Estase Gástrica } & 0,147 & 0,252 & 0,583 & 0,5610 \\ \text { Grupo Pós-Programa Educacional } & -0,532 & 0,166 & -3,213 & \mathbf{0 , 0 0 1 8}\end{array}$

\section{Modelo FINAL:}

\begin{tabular}{lcccc} 
Efeito & Estimativa & E.P. & t-valor & p-valor \\
Intercepto & 3,085 & 0,096 & 32,25 & $<\mathbf{0 , 0 0 0 1}$ \\
Grupo Pós-Programa Educacional & $-0,583$ & 0,135 & $-4,312$ & $<\mathbf{0 , 0 0 0 1}$ \\
\hline E.P: erro padrão & & & &
\end{tabular}


Discussão 


\section{DISCUSSÃO}

\subsection{Dos MÉTodos}

Para elaboração do programa educacional utilizado no presente estudo, foram desenvolvidos protocolos baseados na Diretriz Canadense de Terapia Nutricional para o Doente Crítico $^{3}$, por se tratar de uma diretriz que sofre constantes atualizações de seu conteúdo e já ter sido utilizada em outros trabalhos de caráter educacional e de melhoria de qualidade da terapia nutricional ${ }^{20,21}$.

Optamos por desenvolver um programa de educação nutricional associado à criação dos protocolos nutricionais porque buscam padronizar e automatizar a indicação e o controle da TN na UTI. A implantação de protocolos em UTI está associada à melhoria da qualidade da TN na UTI, portanto, a presença de protocolos nutricionais é cuidado básico e deve constar em qualquer UTI ${ }^{18}$.

A implantação de protocolos de condutas nutricionais em uma UTI deve contemplar a interação de múltiplos fatores associados ao tipo de protocolo, processo de implantação, características da instituição e ao perfil da equipe da UTI ${ }^{38}$. O sucesso da implantação e execução de um protocolo de conduta nutricional reside na sua simplicidade ${ }^{39}$ e personalização para 0 perfil específico de cada UTI. Portanto, para maior efetividade esses protocolos devem contemplar, além do embasamento científico das recomendações oferecidas por diretrizes, sua adaptação à realidade do serviço, clareza, concisão e formato agradável ${ }^{18}$. 
Os cinco protocolos de conduta nutricional desenhados no presente estudo buscaram abranger os problemas mais frequentemente encontrados durante a análise dos dados obtidos na primeira fase do presente estudo. Os nossos protocolos também foram criados visando atender às recomendações internacionais adaptadas à realidade da nossa UTI, que apresenta particularidades comuns às UTIs de hospitais escola públicos brasileiros (poucos recursos humanos, falta de algumas fórmulas nutricionais enterais, grande rotatividade de médicos residentes).

Para melhor assimilação e aplicação dos protocolos desenhados para a condução de nosso estudo também se buscou compreender a rotina e os processos de atendimento da UTI. O programa de educação médica foi personalizado para o perfil particular dos médicos intensivista atuantes em nossa UTI e direcionado pelos princípios educacionais propostos por Weinsier e cols ${ }^{40}$. De acordo com esses autores, programas educacionais em nutrição devem contar com a participação ativa de especialista em nutrição clinica e incluir discussões sobre os aspectos nutricionais dos pacientes, aulas expositivas e discussões à beira leito sobre TN, além de contar com a participação de uma equipe multiprofissional na UTI ${ }^{36}$.

Portanto, inspirado em Weinsier e cols ${ }^{36}$ nosso programa de educação continuada foi estruturado contemplando visitas à beira leito com discussão de casos de um médico especialista em TN com a equipe médica da UTI (diarista, plantonistas e residentes), aulas para explicação dos protocolos de conduta em TN e elaboração de cartazes com os protocolos de conduta. Seu impacto na assimilação de conhecimentos em TN foi 
avaliado por testes com questões idênticas, aplicados antes e após seu desenvolvimento. O mesmo conteúdo das questões no pré e pós-testes teve o intuito de evitar diferenças quanto ao nível de dificuldade das provas, o que poderia interferir na análise dos resultados. Todavia, durante 0 período de treinamento, os tópicos referentes à prova poderiam ser melhor memorizados pelos médicos. Portanto, reconhecemos que o primeiro exame poderia constituir experiência de aprendizagem e, eventualmente, influenciar o desempenho no segundo exame, o que consistiu limitação em nossos resultados.

\subsection{Dos Resultados}

O principal achado do nosso estudo foi o impacto positivo da introdução de um programa de educação em TN para médicos intensivistas na melhoria da qualidade da TN empregada e na redução do tempo de permanência na UTI.

\subsubsection{CARACTERÍSTICAS dA POPULAÇÃO}

Os grupos de pacientes avaliados nas fases pré-programa educacional (PP) e pós-programa educacional (PO) apresentaram características demográficas similares, exceto em relação ao índice de massa corporal (IMC), que foi significativamente maior no grupo PP do que no PO. No entanto, os pacientes apresentaram valores de IMC dentro dos limites de valores normais e de sobrepeso, o que poderia neutralizar o efeito dessa diferença sobre nossos resultados. Isso não parece ter tido um 
impacto clínico em nossos resultados, visto que geralmente os piores resultados em UTI são mais observados em pacientes que estão classificados como desnutridos ou gravemente obesos ${ }^{41}$.

Quando comparamos o IMC e os desfechos clínicos de nossa população com os de outros estudos encontramos resultados conflitantes. Alberda e colaboradores ${ }^{42}$ observaram em seu estudo em doentes críticos que a maior ingestão energética se associou a menor mortalidade em pacientes com $\mathrm{IMC}<25 \mathrm{Kg} / \mathrm{m}^{2}$ ou $\geq 35 \mathrm{Kg} / \mathrm{m}^{2}$. Os autores não encontraram o mesmo benefício para pacientes que apresentaram IMC ente 25 e 34,9 $\mathrm{Kg} / \mathrm{m}^{2}{ }^{42}$. Por outro lado, não houve qualquer associação entre o IMC e o tempo de permanência na UTI ${ }^{42}$. Já em nosso estudo, não houve alteração da mortalidade associada ao aumento da oferta energética, todavia, observamos redução do tempo de permanência na UTI. Talvez o pequeno número de doentes e o perfil cirúrgico da população expliquem, em parte, essa diferença entre os nossos achados e os de Alberda e colaboradores ${ }^{42}$.

\subsubsection{QUALIDADE DA TN}

Sempre que possível, deve-se utilizar a TNE que está associada à redução de complicações infecciosas e tempo de internação hospitalar quando comparada à terapia de nutrição parenteral ${ }^{13}$. Depois da implantação de nosso programa educacional, observamos redução significante do uso de terapia de nutrição parenteral e aumento do uso de terapia nutricional enteral. Isto está de acordo com nosso protocolo implantado na UTI e pode ter influenciado, em parte, a redução do tempo de 
permanência na UTI. Os nossos resultados clínicos, após o programa de educação em terapia nutricional, estão de acordo com as boas práticas mundialmente recomendadas e com o observado em estudo multicêntrico internacional $^{7}$, onde $69 \%$ dos pacientes receberam TNE, $8 \%$ TNP, e $17,6 \%$ a complementariedade de TNE e TNP.

Quando iniciada precocemente $(<48$ horas da admissão do paciente), a TNE está associada ainda à redução de pneumonia e de mortalidade geral ${ }^{7}$. Em nosso estudo, semelhante ao observado por Doig et al. ${ }^{39}$, houve aumento significativo na introdução precoce de NE e redução nos dias de jejum. Essas mudanças são consideradas boas práticas clínicas, de acordo com as diretrizes internacionais ${ }^{3,6-7}$, e podem reduzir risco de infecção, tempo de hospitalização e até mesmo a mortalidade de pacientes em estado crítico ${ }^{35}$.

A maior oferta de energia e adequação da oferta energética recebida em relação à estimada, observadas após a implantação do nosso programa de educação médica em TN, também compreendem um achado favorável de qualidade de TN. Ocorre que pacientes críticos que recebem menos de 25\% da energia recomendada têm maior número de infecções primárias na corrente sanguínea, em comparação com aqueles que recebem mais de $25 \%$ da oferta energética estimada ${ }^{43}$. Em nosso estudo, após o programa educacional, a oferta de energia aumentou em $50 \%$ (77,3\% vs $98,8 \%$ da meta), superando a quantidade média de energia geralmente oferecida a enfermos na UTI (50\% das necessidades calóricas estimadas) ${ }^{38}$. 
De acordo com nossos dados, houve ainda correlação negativa entre quantidade e adequação de energia oferecida e o tempo de permanência (dias) na UTI, o que sugere que o aumento dessas variáveis de TN pode estar associado com diminuição do tempo de permanência na UTI, ambos obervados após o desenvolvimento do nosso programa de educação médica.

\subsubsection{TEMPO DE PERMANÊNCIA NA UTI}

Ao analisar nossas observações em conjunto, é possível sugerir que a diminuição no tempo de permanência na UTI esteja associada com a melhora global da qualidade da TN, após o programa educacional ${ }^{42}$. Fato este endossado através da análise multivariável de quase verossimilhança, na qual nenhuma das possíveis variáveis de confusão alcançou, isoladamente, significância estatística, permanecendo apenas o efeito conjunto do treinamento. Este achado fortalece ainda mais a necessidade de educação médica em terapia nutricional. Oferecer TN adequada parece alterar de maneira positiva o desfecho clínico do paciente crítico, aumentar o tempo livre de ventilação, reduzir as taxas de infecção de corrente sanguínea e diminuir permanência em UTI e no hospital ${ }^{2,42,44}$.

Realizar a implantação de protocolos, seguido por auditorias para verificação de sua utilização, parece ser fundamental para se garantir bons resultados. Outros estudos avaliaram o impacto da introdução de protocolos de conduta nutricional e ferramentas educacionais na qualidade da TN e no desfecho clínico de pacientes criticamente enfermos. No mais recente, Soguel e colaboradores mediram o impacto clínico de um programa 
interdisciplinar de melhoria da qualidade nutricional ${ }^{45}$. Eles encontraram uma melhora importante na qualidade global da terapia nutricional, como observamos em nosso estudo. As melhorias relatadas por Soguel e cols foram associadas à auditoria de um nutricionista dentro da UTI ${ }^{45}$. Isso diferencia o nosso estudo e o de Soguel e colaboradores de outros estudos realizados anteriormente ${ }^{7,46,47}$, nos quais protocolos de alimentação foram implantados sem o emprego de discussões à beira do leito ou auditoria para observar as principais dificuldades e barreiras. Cahil e colaboradores ${ }^{46}$ discutiram em seu estudo a importância da auditoria para favorecer maior aderência durante a implantação de protocolos baseados em diretrizes. Fato este ressaltado por Jain e colaboradores, que atribuiram os resultados abaixo dos esperados durante a implantação de um protocolo de conduta nutricional à falta de auditoria em $64 \%$ das UTIs ${ }^{47}$.

A adequação da TN pode ser um desafio, especialmente nos pacientes críticos cirúrgicos, devido às dificuldades em restabelecer a alimentação por via enteral nesses pacientes, em comparação com outras populações. Isso ocorre principalmente quando o trato gastrointestinal foi manipulado cirurgicamente, como foi o caso da maioria dos pacientes avaliados no nosso estudo. As complicações comuns neste cenário, como íleo pós-operatório, vômitos, diarreia, distúrbios eletrolíticos, alterações da consciência são frequentemente considerados obstáculos importantes para a utilização de NE. Em nosso estudo, essas complicações foram contempladas nos protocolos de TN implantados na UTI, o que pode ter influenciado, em parte, a redução do tempo de permanência na UTI. 
No presente estudo, apesar das evidências levantadas, a inferência de relação causa e efeito entre a melhora da qualidade de TN e diminuição do tempo de permanência na UTI é fraca, pelo tipo de desenho do estudo. No entanto, é possível afirmar que a implantação de um programa educacional visando melhorar o conhecimento médico sobre TN foi associada à melhora da qualidade da TN e se associou à redução do tempo de permanência na UTI.

\subsubsection{EDUCAÇÃO MÉDICA EM TERAPIA NUTRICIONAL}

Nossos achados indicam que, em muitos casos, oferecer TN adequada pode não depender exclusivamente das condições clínicas de um paciente específico, mas também do conhecimento da equipe médica sobre TN e sua criteriosa aplicação. Esse problema foi revisto anteriormente por Adams ${ }^{48}$. O autor reconhece que a educação médica tradicional nos Estados Unidos não fornece aos futuros médicos a quantidade e a qualidade adequada de conhecimento sobre TN para atender às necessidades da prática clínica. Essa observação não é uma realidade exclusiva dos Estados Unidos e parece ocorrer em todo o mundo.

Na Escandinávia, 39\% dos médicos e enfermeiros declararam-se incapazes de diagnosticar desnutrição e 53\% disseram ter dificuldade para calcular a necessidade energética estimada de seus pacientes ${ }^{48}$. Nos Estados Unidos, a principal barreira para o uso de TN foi considerada a falta de confiança dos médicos nos reais efeitos da TN, apesar de concordarem ser esta importante ferramenta para fornecer quantidade adequada de 
nutrientes para seus pacientes ${ }^{49}$. Os principais fatores apontados como responsáveis por esta falta de confiança foram pouca familiaridade com as diretrizes atuais, muitas recomendações baseadas apenas em opiniões de especialistas, falta de formação científica e dificuldades de integração entre dogmas do passado com as diretrizes atuais ${ }^{49}$. Em um estudo na América do Sul, $70 \%$ dos médicos entrevistados relataram não ler artigos sobre nutrição em revistas científicas, apenas 30\% assistiram a alguma atividade educacional sobre nutrição durante os últimos cinco anos e apenas $25 \%$ se sentiram capazes de prescrever nutrição parenteral na prática diária ${ }^{50}$. No mesmo estudo, o conhecimento dos médicos sobre TN, medido através de uma prova com questões de múltipla escolha, foi considerado ruim ${ }^{50}$.

A falta de conhecimento sobre nutrição clínica poderia ser compensada por atividades educacionais alternativas, por exemplo, durante os programas de residência, bem como em outras fases da vida médica. Nesse sentido, a aplicação de um programa de treinamento dirigido a médicos residentes de saúde da família foi realizada por um médico especialista em nutrição ${ }^{49}$. Verificou-se melhora do conhecimento médico sobre nutrição e impacto positivo sobre as práticas médicas após o programa.

Em conjunto, essas observações sugerem que a educação em TN para estudantes de medicina e médicos intensivistas é insatisfatória em todo o mundo e denotam a importância da implantação de programas educacionais, a fim de melhorar a qualidade da TN para pacientes críticos. 


\subsubsection{LIMITAÇÕES}

Existem limitações em nosso estudo, que incluem ausência de padronização anterior de TN na UTI em que foi conduzido o estudo, afinal o fornecimento adequado de TN para pacientes internados em UTI é considerado cuidado básico. Porém, mesmo em hospitais onde os protocolos existem já se relatou falta de cumprimento de metas para realização de $\mathrm{TN}$ adequada ${ }^{51}$. Também devemos considerar que nosso estudo foi conduzido em um único hospital, incluiu pequeno número de médicos e uma pequena diversidade de pacientes. Muitos fatores podem influenciar a permanência na UTI e é impossível ajustar os resultados para fatores de confusão desconhecidos pelo tipo de desenho deste estudo. Esperamos ser capazes de realizar um estudo randomizado e controlado no futuro, que inclua mais centros de UTI. 


\subsection{Perspectivas}

No sentido de ampliar e confirmar os resultados apresentados na presente pesquisa, temos a intenção de, em conjunto com profissionais da saúde do complexo $\mathrm{HC}$, expandir o presente modelo de educação médica em TN para as demais UTIs existentes no Hospital das Clínicas da FMUSP. Esta iniciativa poderia compreender número maior de médicos e acompanhar um número mais expressivo de pacientes. No momento, está em discussão na Comissão de Nutrição em UTI do Complexo HC a estrutura necessária para viabilizar esse novo projeto.

Sabe-se que educação em saúde deve ser um processo contínuo e com repetido controle de qualidade. Assim, em futuro breve temos a intenção de reavaliar a qualidade da TN na mesma UTI foco do presente estudo. É possível que, em razão da alta rotatividade de médicos, a qualidade da TN possa ter se alterado novamente e a aderência aos protocolos criados possa ter diminuido. Caso isso seja confirmado, será necessário redesenhar o projeto de educação contemplando metodologia de educação continuada. É possível que o processo de educação continuada, em conjunto com auditorias frequentes, seja crucial para manter qualidade adequada em TN. Mais do que isso, ao realizar um projeto de educação continuada estaremos contribuindo para o ensino de jovens médicos sobre temas em TN. Isto possivelmente melhorará a prática de intensivistas do futuro em nutrição clínica. 
Como já disse o educador Paulo Freire: "Onde quer que haja mulheres e homens, haverá sempre o que fazer, sempre o que ensinar, sempre o que aprender". 
Conclusões 


\section{Conclusões}

Nas condições do presente estudo:

1. A aplicação de um novo modelo de educação em terapia nutricional para médicos intensivistas melhorou o conhecimento destes médicos em nutrição clínica.

2. A aplicação prática do maior conhecimento médico em terapia nutricional se refletiu em melhora da qualidade da terapia nutricional realizada.

3. A melhora da qualidade da terapia nutricional realizada foi acompanhada por resultado clínico favorável. 
Anexos 


\section{ANEXOS}

ANEXO A

ÉTICA GASTRO

São Paulo, 16 de outubro de 2008.

IImo. Sr.

Prof. Dr. Dan L. Waitzberg

Prezado Prof. Dr. Dan,

Atendendo sua solicitação, a Comissão Ético-Científica do Departamento de Gastroenterologia da FMUSP, em 16 de outubro de 2008, analisou e aprovou "Ad Referendum" o seu projeto de pesquisa, intitulado: "A INFLUÊNCIA DA INTRODUÇÃO DE UM PROTOCOLO NUTRICIONAL NO DESFECHO DOS PACIENTES EM UMA UNIDADE DE TERAPIA INTENSIVA".

Atenciosamente,

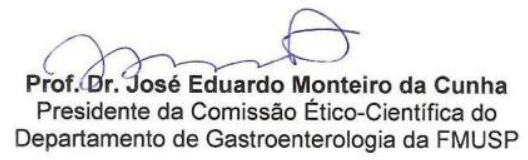




\section{ANEXO B - ETICA CAPPESQ}

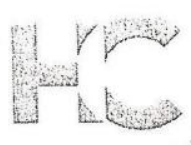

\section{APROVAÇÃO}

A Comissão de Ética para Análise de Projetos de Pesquisa CAPPesq da Diretoria Clínica do Hospital das Clínicas e da Faculdade de Médicina da Universidade de São Paulo, em sessão de 16/12/2009, APROVOU O Protocolo de Pesquisa nº 0929/09, intitulado: "A INFLUENCIA DA INTRODUÇĀO DE UM PROTOCOLO NUTRICIONAL NO DESFECHO DOS PACIENTES EM UMA UNIDADE DE TERAPIA INTENSIVA" apresentado pelo Departamento de GASTROENTEROLOGIA, inclusive o Termo de Consentimento Livre e Esclarecido.

Cabe ao pesquisador elaborar e apresentar à CAPPesq, os relatórios parciais e final sobre a pesquisa (Resolução do Conselho Nacional de Saúde $n^{\circ}$ 196, de 10/10/1996, inciso (X.2, letra "c").

Pesquisador (a) Responsável: Dan L. Waitzberg Pesquisador (a) Executante: Melina Gouveia Castro

CAPPesq, 21 de Dezembro de 2009

$$
\text { a. }
$$

Prof. Dr. Eduardo Massad Presidente da Comissāo de<smiles>CC(C)(C)C1CCC1</smiles>
Ética para Análise de Projetos de Pesquisa

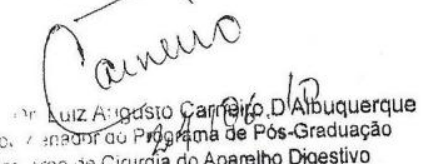

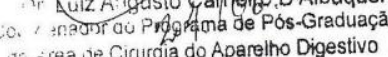

Comissão de Ética para Análise de Projetos de Pesquisa do HCFMUSP e da FMUSP Diretoria Clínica do Hospital das Clínicas da Faculdade de Medicina da Universidade de Săo Paulo Rua Ovidio Pires de Campos, 225, $5^{\circ}$ andar - CEP 05403010 - São Paulo - SP Fone: 01130696442 Fax: 01130696492 e-mail: cappesq@hcnet.usp.br/ secretariacappesq2@hcnet.usp.br 


\section{ANEXO C - TERMO DE CONSENTIMENTO LIVRE E ESCLARECIDO TERMO DE CONSENTIMENTO LIVRE E ESCLARECIDO}

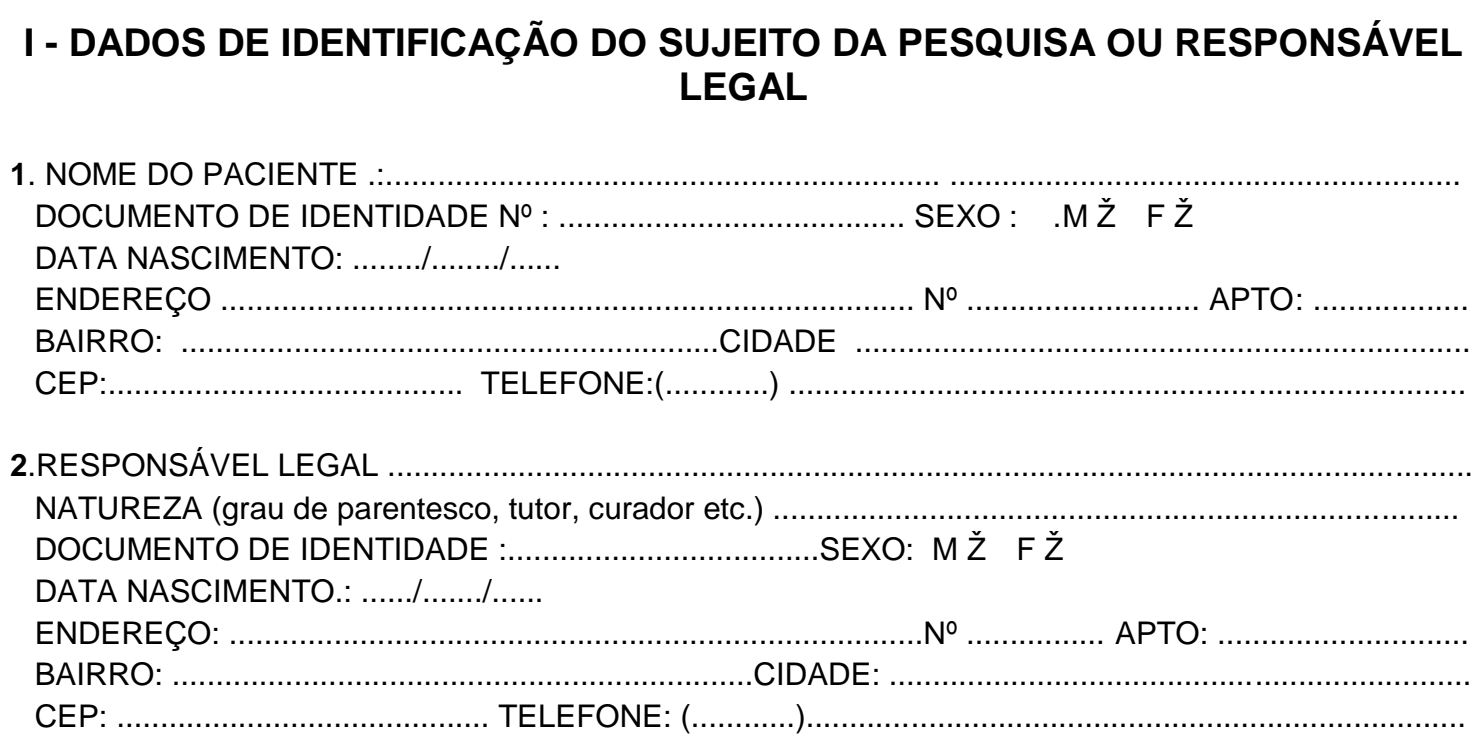

\section{II - DADOS SOBRE A PESQUISA CIENTÍFICA}

1. TÍTULO DO PROTOCOLO DE PESQUISA: "A INFLUENCIA DA INTRODUÇÃO DE UM PROTOCOLO NUTRICIONAL NO DESFECHO DOS PACIENTES EM UMA UNIDADE DE TERAPIA INTENSIVA"

PESQUISADOR: Melina Gouveia Castro

CARGO/FUNÇÃO: Médica INSCRIÇÃO CONSELHO REGIONAL № 113010 CRM SP

UNIDADE DO HCFMUSP: CIRURGIA DO APARELHO DIGESTIVO

3. AVALIAÇÃO DO RISCO DA PESQUISA:

$\begin{array}{llll}\text { SEM RISCO } & \mathbf{X} & \text { RISCO MÍNIMO Ž } & \text { RISCO MÉDIO } \\ \text { RISCO BAIXO } & \check{Z} & \text { RISCO MAIOR } & \text { Ž }\end{array}$

(probabilidade de que o indivíduo sofra algum dano como conseqüência imediata ou tardia do estudo)

4.DURAÇÃO DA PESQUISA : Aproximadamente 2 anos.

\section{III - REGISTRO DAS EXPLICACCÕES DO PESQUISADOR AO PACIENTE OU SEU REPRESENTANTE LEGAL SOBRE A PESQUISA CONSIGNANDO:}

1. justificativa e os objetivos da pesquisa 
O objetivo consiste em estabelecer um protocolo de condutas em terapia nutricional que possa contribuir para um incremento da qualidade do atendimento na unidade de terapia intensiva e consequentemente um maior benefício ao paciente crítico.

2. procedimentos que serão utilizados e propósitos, incluindo a identificação dos procedimentos que são experimentais

Para participar do estudo, você deverá se encaixar em alguns critérios. Caso seu médico/nutricionista decida que você preenche os critérios, você irá assinar um formulário de consentimento e será inserido no estudo. Para esta pesquisa vamos realizar apenas a coleta de dados relativos a terapia nutricional consistentes no prontuário.

3. desconfortos e riscos esperados

Não são esperados desconfortos relacionados a pesquisa tendo em vista que baseia-se unicamente na coleta de dados e observação da evolução do paciente. Na segunda fase a intervenção será realizada quanto a introdução e manipulação da terapia nutricional, baseada em protocolos de conduta.

4. benefícios que poderão ser obtidos

Através da avaliação dos dados nutricionais poderemos estabelecer um protocolo de conduta que melhore a qualidade da terapia nutricional e a evolução clínica dos pacientes internados na unidade de terapia intensiva.

\section{IV - ESCLARECIMENTOS DADOS PELO PESQUISADOR SOBRE GARANTIAS DO SUJEITO DA PESQUISA CONSIGNANDO:}

1. acesso, a qualquer tempo, às informações sobre procedimentos, riscos e benefícios relacionados à pesquisa, inclusive para dirimir eventuais dúvidas.

Você tem o direito de acessar seus registros médicos e informações sobre os procedimentos de acordo com as leis nacionais a qualquer momento com o intuito de sanar possíveis dúvidas.

2. liberdade de retirar seu consentimento a qualquer momento e de deixar de participar do estudo, sem que isto traga prejuízo à continuidade da assistência.

Se você decidir participar deste estudo, você poderá sair dele a qualquer momento sem qualquer prejuízo, e isso não afetará de modo algum os cuidados futuros a serem recebidos de seu médico, seu nutricionista ou hospital. 
3. salvaguarda da confidencialidade, sigilo e privacidade.

As informações da pesquisa não serão transmitidas exceto para profissionais especializados, e sem jamais revelar seu nome ou identidade.

4. disponibilidade de assistência no HCFMUSP, por eventuais danos à saúde, decorrentes da pesquisa.

Caso haja alguma ocorrência decorrente desta pesquisa, os pacientes deverão entrar em contato com Dr Dan L. Waitzberg, através do telefone: 3062-0841.

5. viabilidade de indenização por eventuais danos à saúde decorrentes da pesquisa.

Não haverá indenização aos pacientes, porque esta pesquisa, não envolve danos ou riscoa à saúde dos mesmos.

\section{INFORMAÇÕES DE NOMES, ENDEREÇOS E TELEFONES DOS RESPONSÁVEIS PELO ACOMPANHAMENTO DA PESQUISA, PARA CONTATO EM CASO DE INTERCORRÊNCIAS CLÍNICAS E REAÇÕES ADVERSAS.}

Médica: Melina Gouveia Castro- 3062-0841 / 3069-7560 (ramal 106) / 9831 9999 ou Prof. Dr. Dan L. Waitzberg - 3062-0841.

\section{OBSERVAÇÕES COMPLEMENTARES:}

\section{VII - CONSENTIMENTO PÓS-ESCLARECIDO}

Declaro que, após convenientemente esclarecido pelo pesquisador e ter entendido o que me foi explicado, consinto em participar do presente Protocolo de Pesquisa
São Paulo,
de
de 200_.

assinatura do sujeito da pesquisa

ou responsável legal assinatura do pesquisador

(carimbo ou nome Legível) 


\section{ANEXO D - Ficha de Inclusão de Pacientes}

Ficha de Inclusão de Pacientes

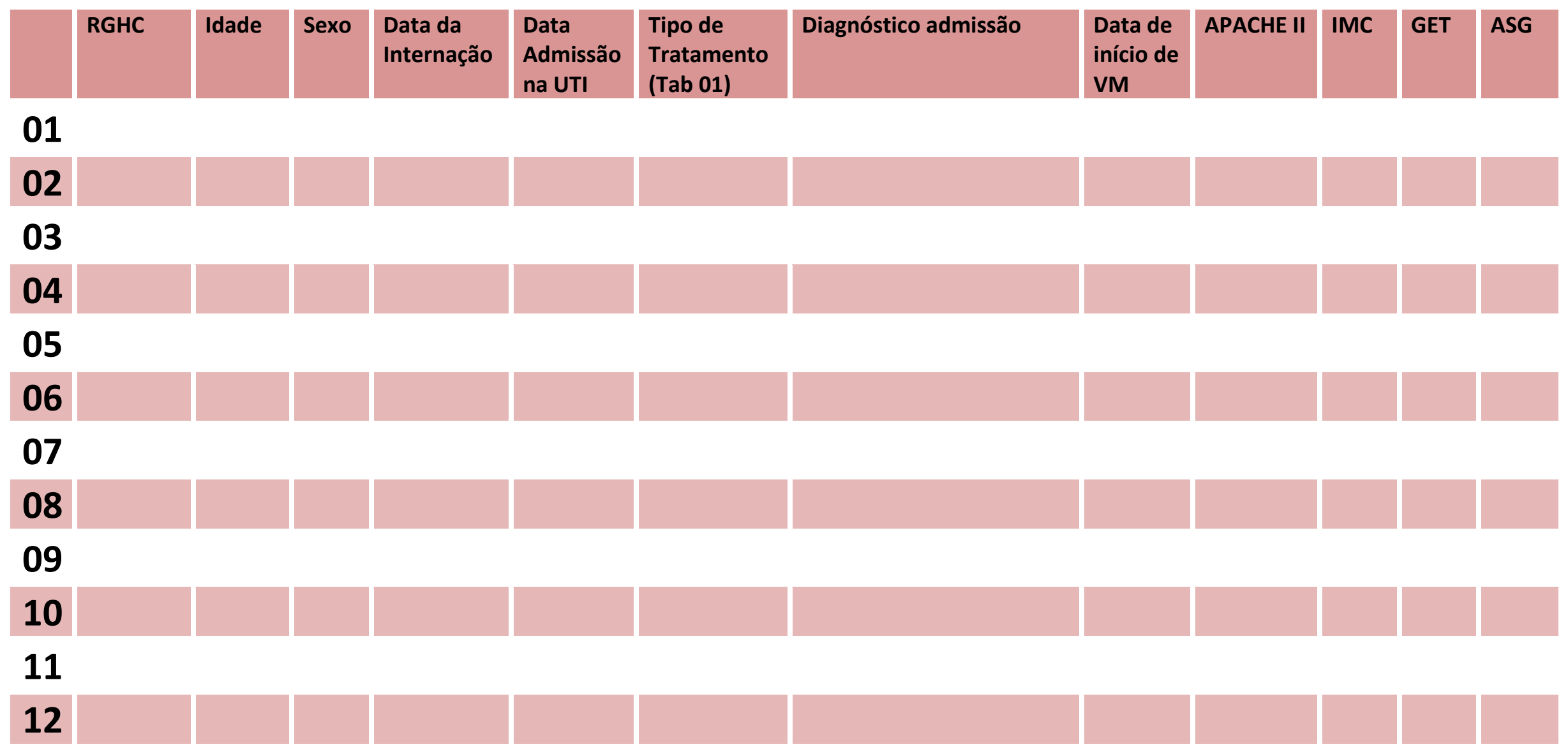




\section{Anexo E - Ficha de Acompanhamento Diário}

\section{Evolução Diária do Suporte Nutricional}

Paciente $\mathrm{n}$.

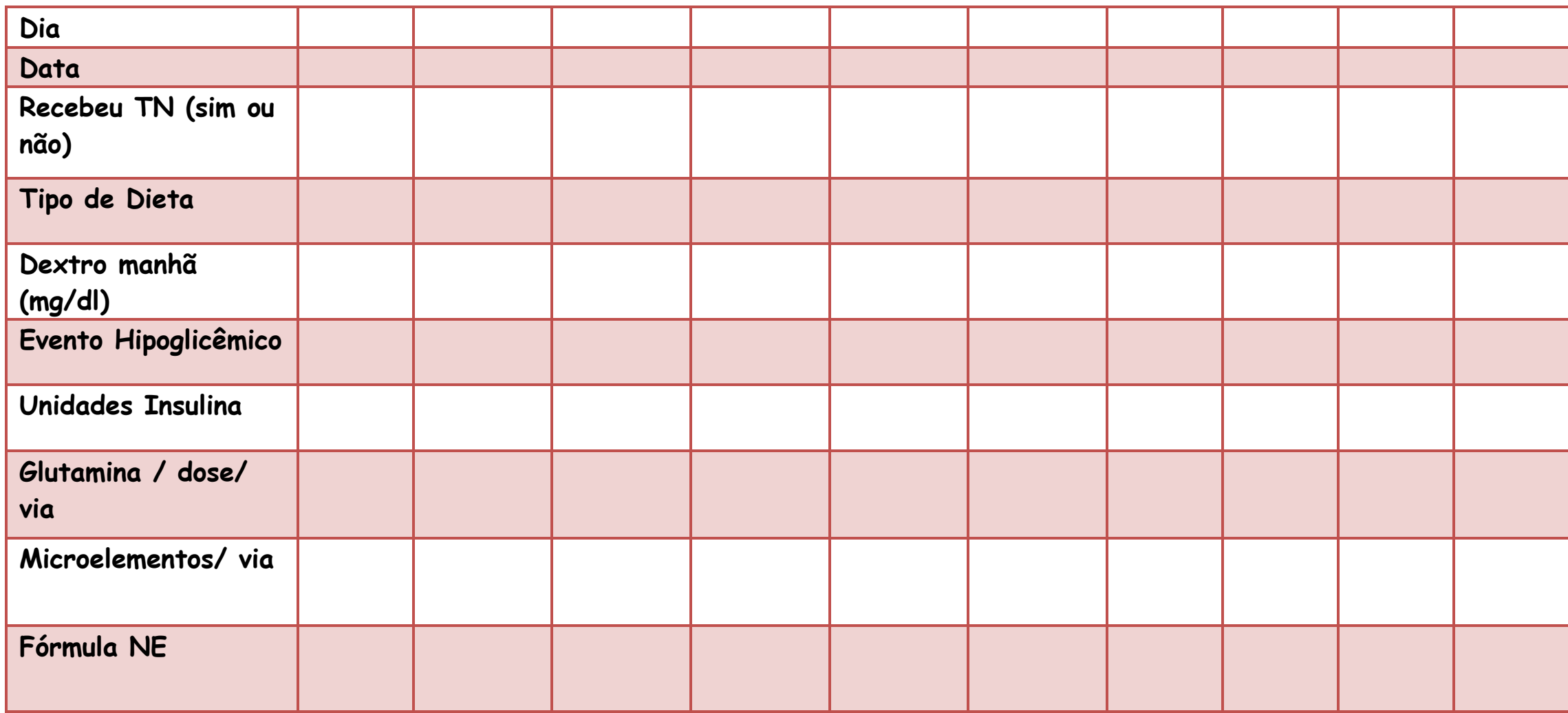




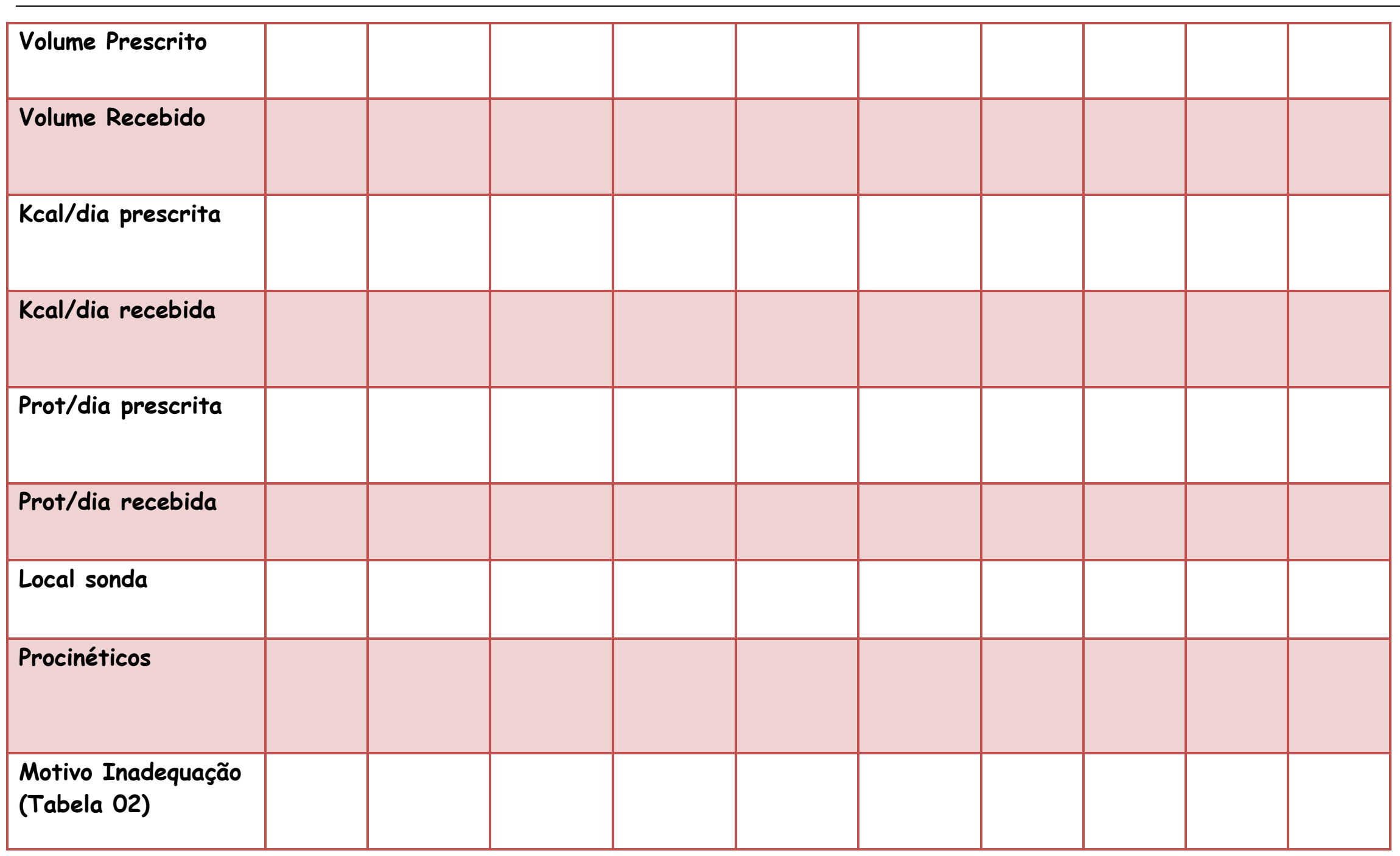




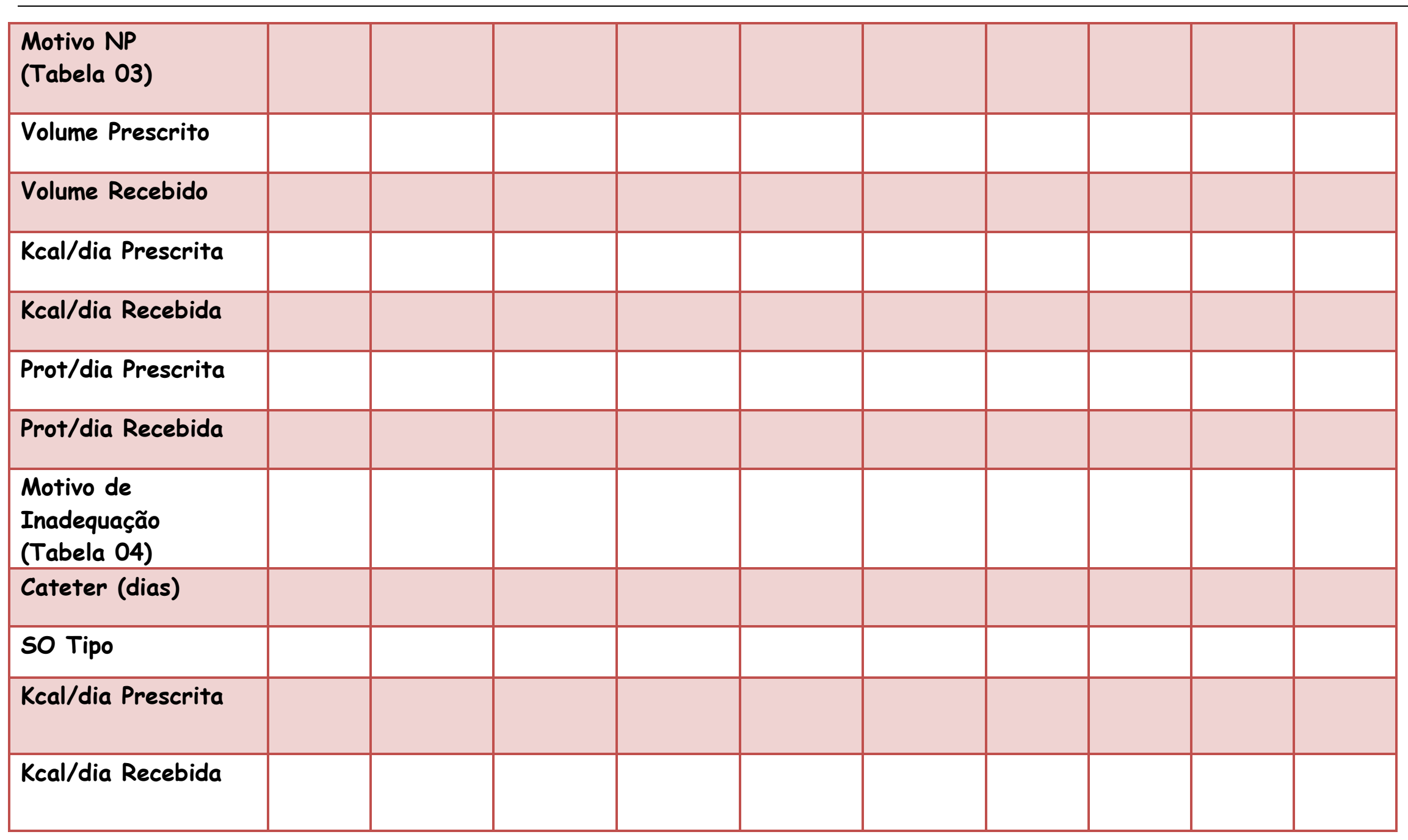




\begin{tabular}{|l|l|l|l|l|l|l|l|l|l|}
\hline Prot/dia Prescrita & & & & & & & & & \\
\hline Prot/dia Recebida & & & & & & & & & \\
\hline $\begin{array}{l}\text { Motivo de } \\
\text { Inadequação } \\
\text { (Tabela 05) }\end{array}$ & & & & & & & & & \\
\hline
\end{tabular}


Tabela 01 - Tipo de Tratamento

01 Cirúrgico Eletivo

02 Cirúrgico urgência/emergência

03 Clínico por indicação

04 Clínico por falta de condições cirúrgicas

05 Outros

Tabela 02 - Motivo Inadequação NE

01 Jejum para exame

02 Jejum para cirurgia de urgência

03 Jejum para cirurgia eletiva

04 Jejum por condição clínica

05 Vômitos

06 Refluxo aumentado

07 Distensão abdominal

08 Diarréia

09 Hiperglicemia

10 Perda da sonda

11 Obstrução da sonda

12 Ordem médica sem justificativa

13 Atraso da dieta pelo DND

14 Problemas na administração pela enfermagem

15 Complicações logísticas com a dieta

16 Outros 
Tabela 03 - Indicação de Parenteral

\begin{tabular}{ll}
\hline 01 & Obstrução intestinal mecânica \\
02 & Sangramento gastrointestinal \\
03 & Íleo paralítico \\
04 & Fístulas de alto débito \\
05 & Isquemia gastrointestinal \\
06 & Inviabilidade de acesso ao intestino \\
07 & Má absorção grave \\
08 & Falha na progressão de NE \\
09 & Necessidade de complementação calórico protéica \\
10 & Síndrome do intestino curto \\
11 & Intolerância a NE \\
12 & Outros \\
\hline
\end{tabular}

Tabela 04 - Motivo inadequação da NP

\begin{tabular}{ll}
\hline 01 & Atraso na infusão \\
02 & Suspensão por hiperglicemia \\
03 & Suspensão por complicações clínicas \\
04 & Perda do cateter \\
05 & Bacteremia/febre \\
06 & Infecção do cateter \\
07 & Atraso da bolsa pela farmácia \\
08 & Restrição volumérica \\
09 & Ordem médica sem justificativa \\
10 & Colestase \\
\hline 11 & Outros \\
\hline
\end{tabular}


Tabela 05 - Inadequação de Suplementação VO

\begin{tabular}{ll}
\hline 01 & Anorexia \\
02 & Palatabilidade \\
03 & Vômitos \\
04 & Distensão abdominal \\
05 & Diarréia \\
06 & Recusa do paciente \\
07 & Jejum para exame \\
08 & Jejum para cirurgia de urgência \\
09 & Jejum para cirurgia eletiva \\
10 & Jejum por condição clínica \\
11 & Atraso da dieta pelo DND \\
\hline 12 & Outros \\
\hline
\end{tabular}




\section{Anexo F - Ficha de Alta}

EVOLUÇÃO DE T N E INDICADORES DE QUALIDADE

I - Dados do Paciente:

Diagnóstico principal:

Comorbidades:
DM
HAS
DPOC $\square$ Nefropatia
Hepatopatia
Cardiopatia

Outras:

Data da internação:

Data de admissão na UTI:

Data da avaliação nutricional:

Data de inicio da terapia nutricional:

Data de interrupção da terapia nutricional:

Tempo de jejum:

\begin{tabular}{|l|l|}
\hline Menor $24 \mathrm{~h}$ & \\
\hline Maior $24 \mathrm{~h}$ & \\
\hline $\begin{array}{l}\text { Número de } \\
\text { dias }\end{array}$ & \\
\hline
\end{tabular}

\begin{tabular}{|l|l|}
\hline $80-100 \%$ NC & \\
\hline $60-79 \%$ NC & \\
\hline $40-59 \%$ NC & \\
\hline $20-39 \%$ NC & \\
\hline Menor $19 \%$ NC & \\
\hline
\end{tabular}

Data da operação:

Data da reoperação:

Tipo:

Tipo:

Dias de acompanhamento:

Data de saída da UTI: 
Data de alta hospitalar ou óbito:

$\square$ alta

óbito

$\square$ com NE

$\square$ relacionado a complicações de TN

com NP

não relacionado

com complemento oral

transferência par Hospital de retaguarda

com dieta oral

II - Dados Clínicos:

Triagem

A S G inicial

Tipo de T N

$\begin{array}{llll}\text { Peso usual___ } \_ \text {gg } & \square \text { Não desnutrido } & \square \text { Dieta oral } \\ \text { Peso inicial __ } \_ \text {kg } & \square \text { Desnutrido moderado/risco } \square \text { Dieta oral +Complemento } \\ \text { Peso final } \_\_ \text {kg } & \square \text { Desnutrido grave } & \square \text { Enteral }\end{array}$

IMC $\mathrm{kg} / \mathrm{m}^{2}$

Classificação NRS

Risco Nutricional

Parenteral Periférica

$\%$ Perda de Peso $(6 \mathrm{~m})$

Sem Risco

Enteral+Parenteral

Albumina inicial

Albumina final $\mathrm{mg} / \mathrm{dL}$ $\mathrm{Kg}$ $\mathrm{mg} / \mathrm{dL}$

III - Indicações/condições associadas:

(assinalar doenças associadas caso tenham relação com a indicação da terapia nutricional)

Pré-operatório

Pós-operatório

Câncer de

Transplante de

Trauma

Hipermetabolismo

Septicemia

Insuf. Respiratória (IOT)
Síndrome de Resposta Inflamátória

Síndrome de Disfunção de Múltiplos Órgãos

Doença Neurológica

AVC

Doença gastrintestinal

Fístula

débito: $\square$ alto $\square$ baixo

TGI: $\square$ alto $\square$ baixo 
IV - Necessidades Nutricionais

Estimativa inicial das necessidades nutricionais: $\mathrm{kcal} / \mathrm{dia}$ gptn/Kg/dia

Oferta energética máxima ministrada: kcal por dias $\%)$

Caso $\%$ final menor que $90 \%$, motivo:

Dado não disponível

V - Forma de aquisição e/ou preparo da solução nutritiva

NE nome:

NP

polimérica padrão

sistema glicídico

polimérica hiper hiper

sistema lipídico: $\square$ soja

oligomérica

$\mathrm{TCM} / \mathrm{TCL}$

controle glicemico

oliva

nefropata

peixe

aa ramificados

oligoelementos

imunomoduladora

vitaminas

glutamina

associação de : $\square$ Fibra

Vitaminas

Glutamina

VI - Acesso para a terapia nutricional enteral

sonda nasogástrica $\quad \square$ sonda nasojejunal $\quad \square$ jejunostomia endoscópica

sonda nasoenteral $\square$ gastrostomia endoscópica $\square$ jejunostomia cirúrgica

sonda nasoenteral pós-pilorica $\quad \square$ gastrostomia cirúrgica $\square$ outra

VII - Acesso para terapia nutricional parenteral

cateter venoso periférico

cateter venoso percutâneo central (PICC)

cateter venoso central de curta permanência

cateter central semi/totalmente implantável 
VIII - Complicações relacionadas à terapia nutricional (NE e NP)

$\operatorname{sim}$

$\square$ não

gastrintestinais:

mecânicas relacionadas ao acesso enteral/parenteral:

$\square$ vômitos

obstrução do CVC

$\square$ diarréia

complicação técnica na passagem do CVC

distensão abdominal

obstrução de acesso enteral

estase gástrica

saída acidental de acesso enteral

aspiração pulmonar

infecciosas relacionadas ao acesso venoso central

metabólicas

infecciosas relacionadas ao acesso enteral

hiperglicemia

hipoposfatemia

hipertrigliceridemia 


\section{Anexo G - Avaliação Nutricional Subjetiva Global (ASG)}

\section{Avaliação Nutricional Subjetiva Global}

\section{A - História}

1. PESO

(1) Mudou nos últimos 6 meses ( ) S ( ) N

(1) Continua perdendo atualmente ( ) S ( ) N

(2) Perda de Peso

Kg \% Perda Se $>10 \%(2)(\quad) \quad$ Se $<10 \%(1) \quad(\quad)$ Peso Atual: Peso Habitual:

Peso Internação: Número de dias internado:

\section{DIETA}

(1) Mudança de dieta ( ) S ( ) N A mudança foi para:

(1) ( ) dieta hipocalórica

(1) ( ) dieta pastosa hipocalórica

(2) ( ) dieta líquida $>15$ dias ou solução intravenosa $>5$ dias

(3) ( ) jejum $>5$ dias

(4) ( ) mudança persistente $>30$ dias

\section{SINTOMAS GASTRINTESTINAIS}

(1) ( ) Disfagia e/ou odinofagia

(1) ( ) Náuseas

(1) ( ) Vômitos

(1) ( ) Diarréia

(2) ( ) Anorexia, distensão ou dor abdominal

4. CAPACIDADE FUNCIONAL FÍSICA

(por mais de 2 semanas)

(1) ( ) abaixo do normal

(2) ( ) acamado

5. DIAGNÓSTICO

(1) ( ) Baixo estresse

(2) ( ) Moderado estresse

(3) ( ) Alto estresse

\section{B- Exame Fisico}

( ) Perda de gordura subcutânea ( tríceps, tórax)

( ) Perda de músculo estriado

( ) Edema sacral

( ) Edema de tornozelo

( ) Ascite

\section{C- Categorias ANSG}

( ) Bem nutrido <17 pontos

( ) Moderadamente desnutrido 17 a 22 pontos

( ) Gravemente desnutrido $>22$ pontos 


\section{ANEXO H - Pré e Pós Teste de Terapia Nutricional no Doente Crítico}

1. Qual dessas não é contra indicação absoluta ao uso da via digestiva?

a) a) Obstrução Mecânica Intestinal

b) b) Sangramento Intestinal

c) c) Instabilidade Hemodinâmica

d) d) Isquemia Intestinal

2. Qual acesso de escolha para um paciente, 78 anos, portador de um câncer gástrico que apresenta $10 \%$ de perda de peso em 4 meses, vômitos pós-alimentares, ingestão via oral de cerca de $40 \%$ das necessidades calórico-protéicas e que será submetido a uma gastrectomia total em uma semana?

a) Sonda locada em acesso gástrico no pré-operatório e jejum até reintrodução da dieta via oral no pós-operatório.

b) Nutrição parenteral pré-operatória e sonda locada distalmente a anastomose no pós-operatório

c) Dieta via oral no pré-operatório e nutrição parenteral no pósoperatório até liberação da dieta via oral

d) Sonda locada em acesso gástrico no pré-operatório e sonda locada distalmente a anastomose no pós-operatório

3. Qual condição dentre as abaixo não é um pré-requisito básico para nutrição enteral precoce?

a) Estabilidade hemodinâmica

b) Ausência de distensão abdominal

c) Trato gastrintestinal funcionante

d) Presença de acesso locado distalmente a anastomose (sonda o jejunostomia) 
4. Qual deve ser a meta alvo para progressão da nutrição enteral em um paciente crítico?

a) Atingir $60 \%$ das necessidades em até 5 dias

b) Atingir $90 \%$ das necessidades em até 4 dias

c) Atingir $60 \%$ das necessidades em 7 dias

d) Atingir $90 \%$ das necessidades em 7 dias

5. Qual das medidas abaixo não deve ser realizada quando constatado mais de um episódio de resíduo gástrico maior que $250 \mathrm{ml}$ em $24 \mathrm{~h}$ ?

a) Suspender a dieta e aguardar melhora da gastroparesia

b) Associar mais uma droga procinética

c) Diminuir a velocidade de infusão da dieta

d) Atentar para drogas que possam estar envolvidas aos episódios de gastroparesia

6. Quanto aos procinéticos:

a) Devem ser utilizados apenas se houver episódio de resíduo gástrico aumentado

b) A droga de escolha para o uso em todos os pacientes com nutrição enteral é a eritromicina

c) Deve estar prescrito de rotina para todos os pacientes de UTI

d) Nos paciente em uso de nutrição enteral a metroclopramida deve ser sempre associada

7. Qual a definição padronizada para diarréia?

a) Presença de 3 ou mais episódios de fezes pastosas

b) Presença de 2 ou mais evacuações líquidas em 24 horas

c) Presença de 3 ou mais episódios de fezes líquidas por 2 dias consecutivos 
d) Aumento da frequência e diminuição da consistência das evacuações não importando nem a quantidade exata de evacuações nem a consistência das fezes

8. Qual a primeira medida a ser tomada em um paciente com nutrição enteral e diarréia?

a) Iniciar droga anti diarréica

b) Suspender a dieta

c) Solicitar exames para pesquisar a etiologia do quadro

d) Associar fibra a dieta enteral

9. Após quantos dias de jejum está indicado o uso de nutrição parenteral?

a) Uma semana

b) A partir do terceiro dia

C) A partir do décimo dia

d) No quinto dia

10. As estratégias que devem ser implementadas nos pacientes com nutrição parenteral para uso o mais precoce do trato digestivo, são, exceto:

a) Uso de metroclopramida

b) Checar resíduo gástrico a cada 4 horas

c) Locar sonda jejunal

d) Utilização de glutamina 


\section{Anexo I - Protocolos de Conduta Nutricional}

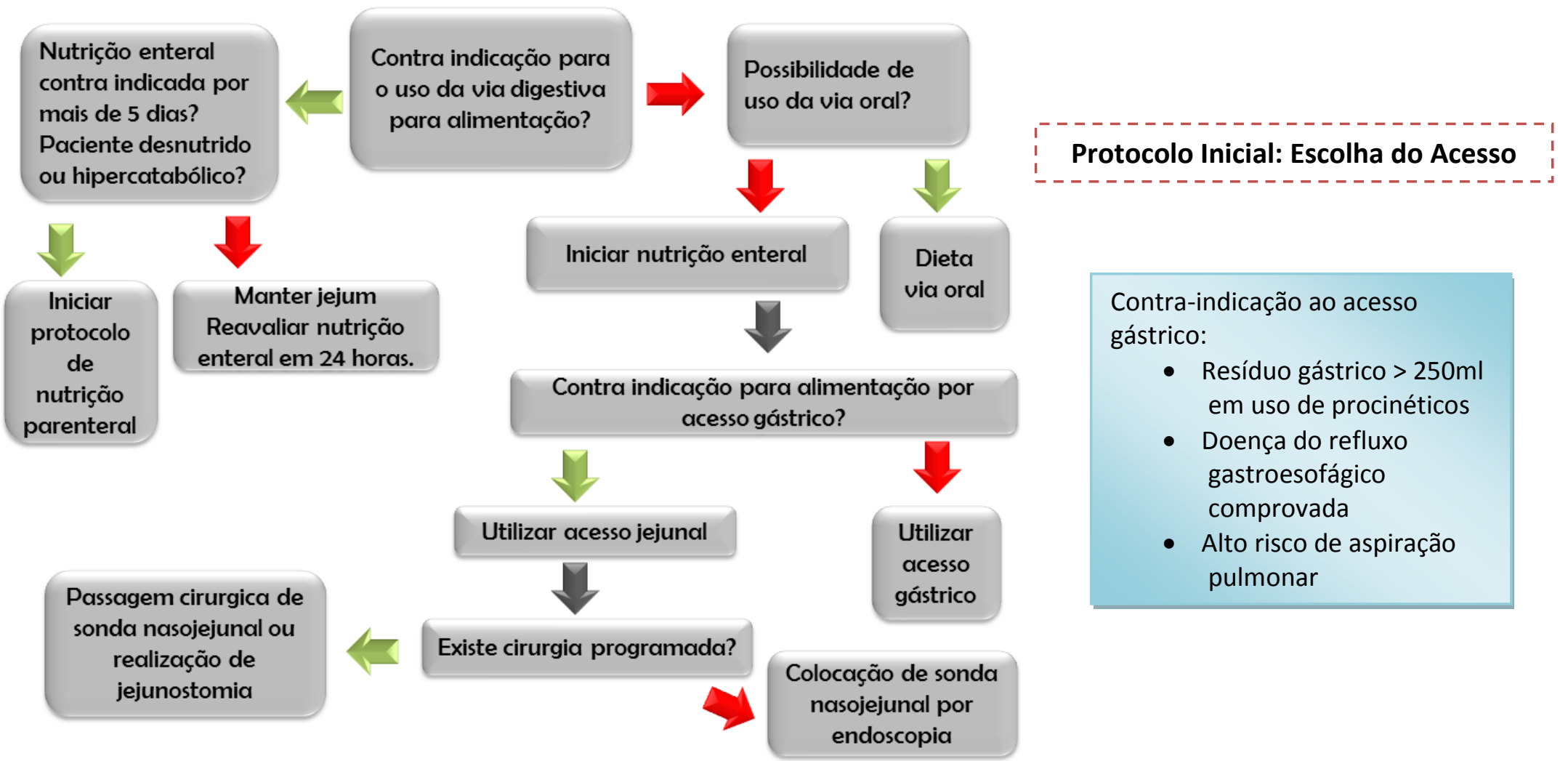

Contra-indicações para nutrição enteral:

Absolutas: obstrução mecânica intestinal, isquemia

intestinal, sangramento intestinal

Relativas: instabilidade hemodinâmica, fístulas,

anastomose intestinal distal a sonda 


\begin{tabular}{|l}
\hline Pré requisitos básicos \\
para NE precoce: \\
- \\
Estabilidade \\
hemodinâmica \\
Trato \\
gastrintestinal \\
funcionante \\
- Presença de \\
jejunostomia \\
ou sonda \\
locada \\
distalmente a \\
anastomose \\
em caso de \\
cirurgia \\
abdominal de \\
grande porte
\end{tabular}

Iniciar Procinéticos

(Metroclopramida

10mg EV q8h)

Manter velocidade

de infusão da dieta

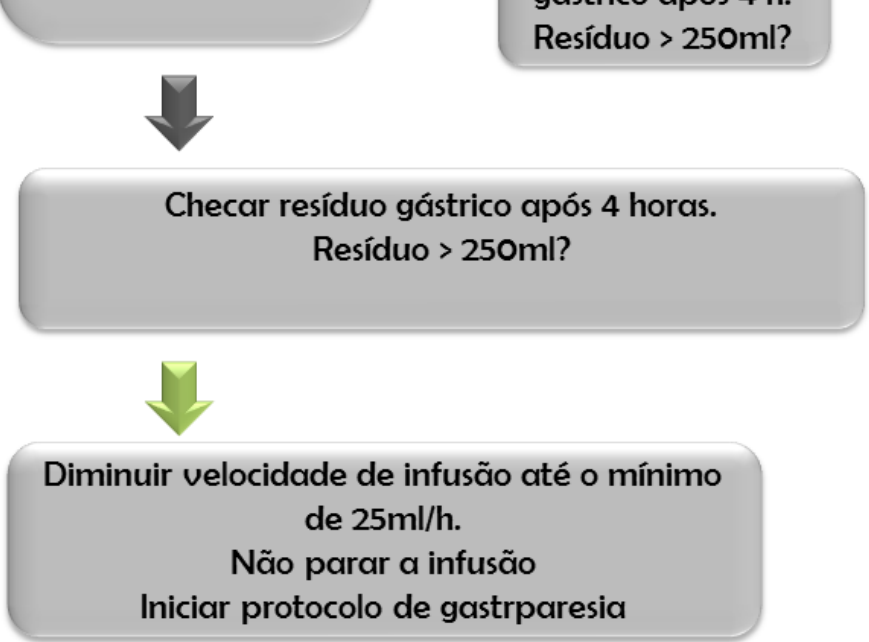

Iniciar NE com fórmula

polimérica em bomba de

infusão contínua na

velocidade de $25 \mathrm{ml} / \mathrm{h}$ em

24 a $48 \mathrm{~h}$ da admissão

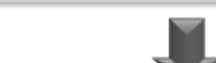

\section{Testar resíduo \\ á́strico após $4 \mathrm{~h}$. \\ Resíduo > 250ml?}
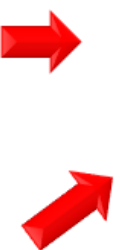

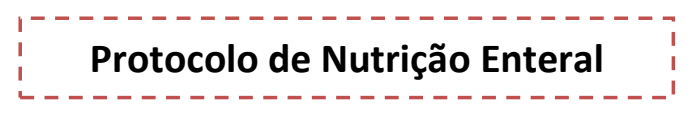

Aumentar velocidade

de infusão da dieta

em $25 \mathrm{ml} / \mathrm{h}$ ao dia, até

atingir necessidade

calórica estimada.

Atingir $\mathbf{9 0} \%$ das

necessidades em até 4

dias.

\section{Necessidade Calóricas Estimadas}

(Fórmula de Bolso)

Fase Aguda:

20 a $25 \mathrm{Kcal} / \mathrm{Kg}$

Fase de Recuperação:

25 a $30 \mathrm{Kcal} / \mathrm{Kg}$ 


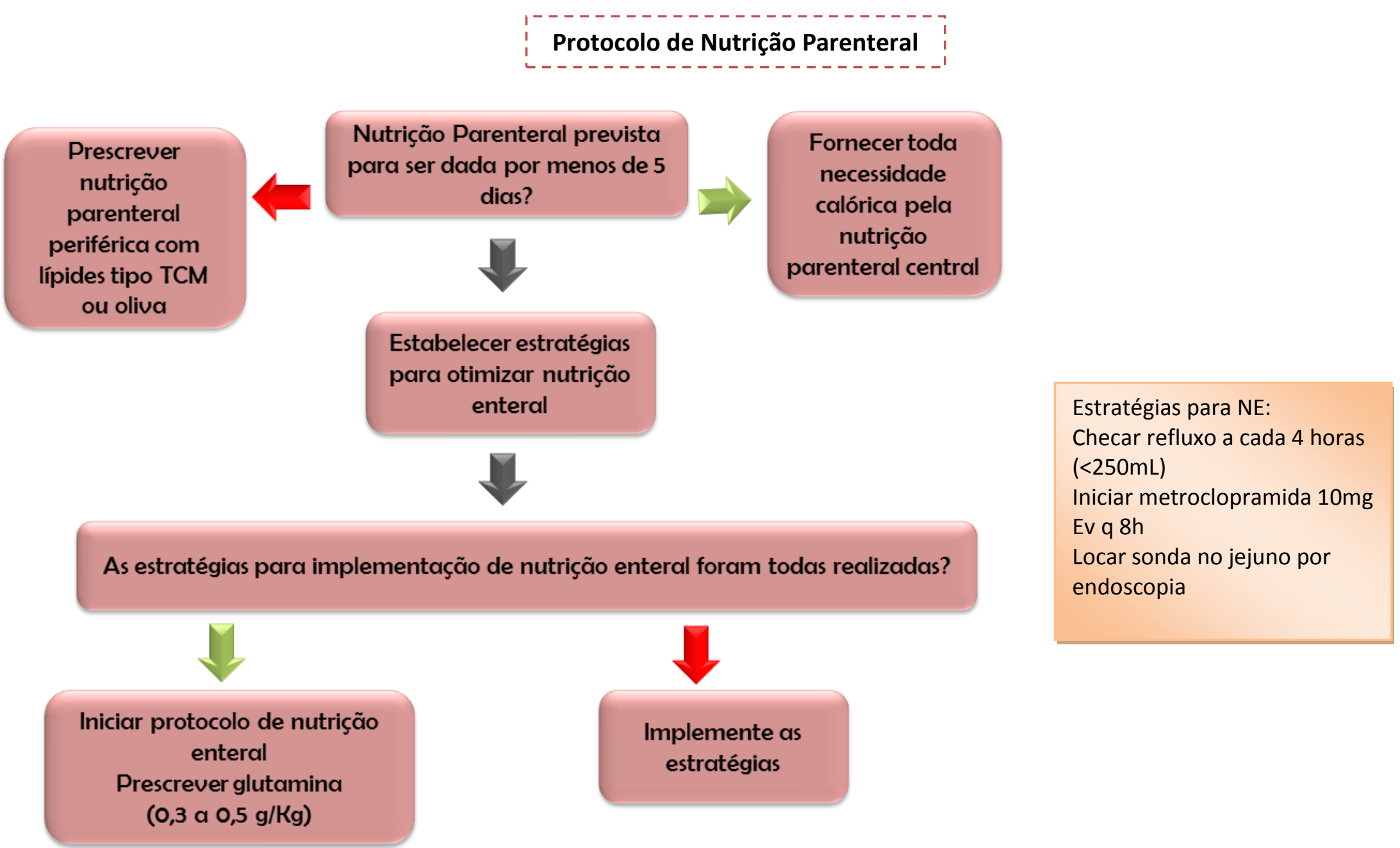




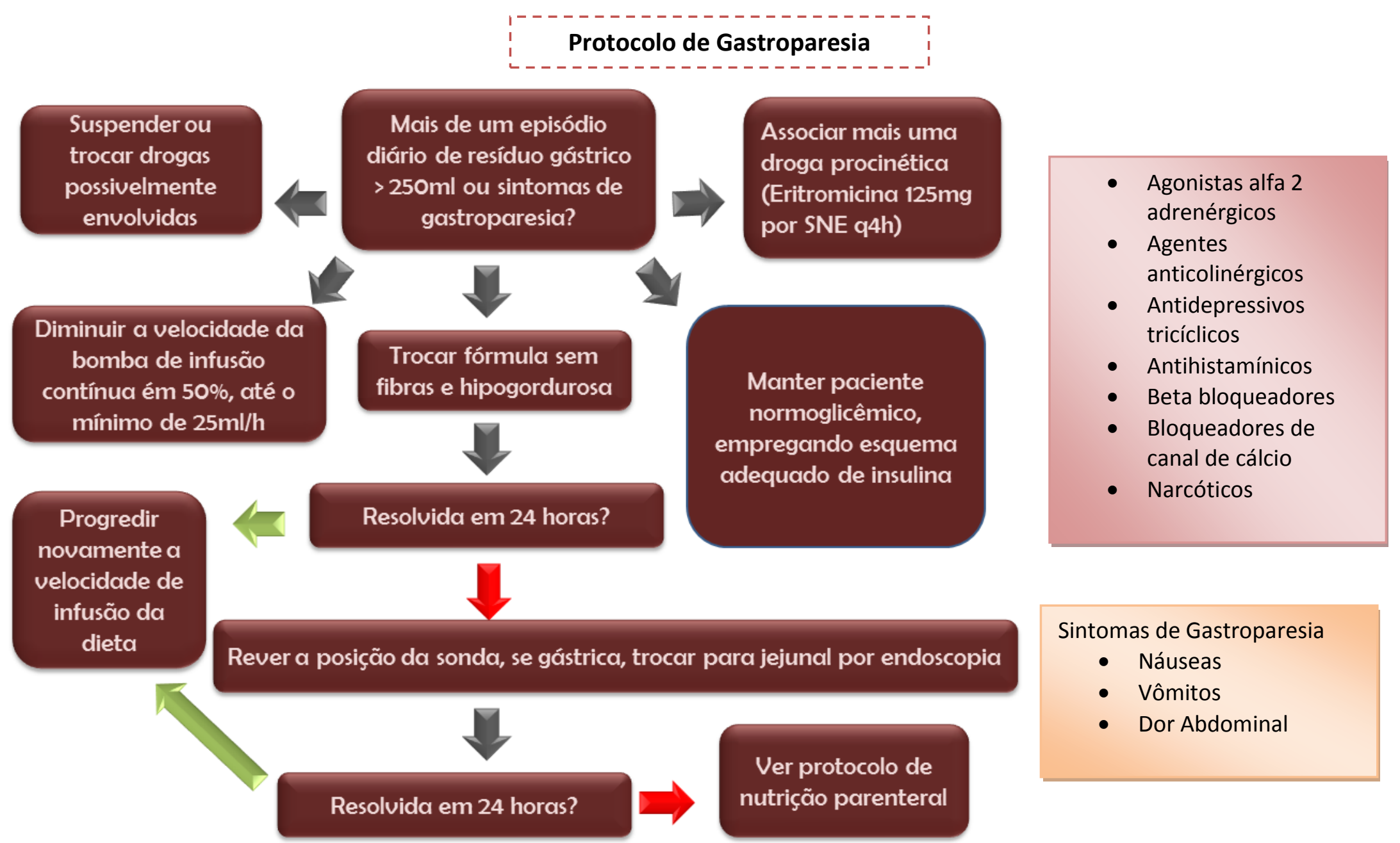




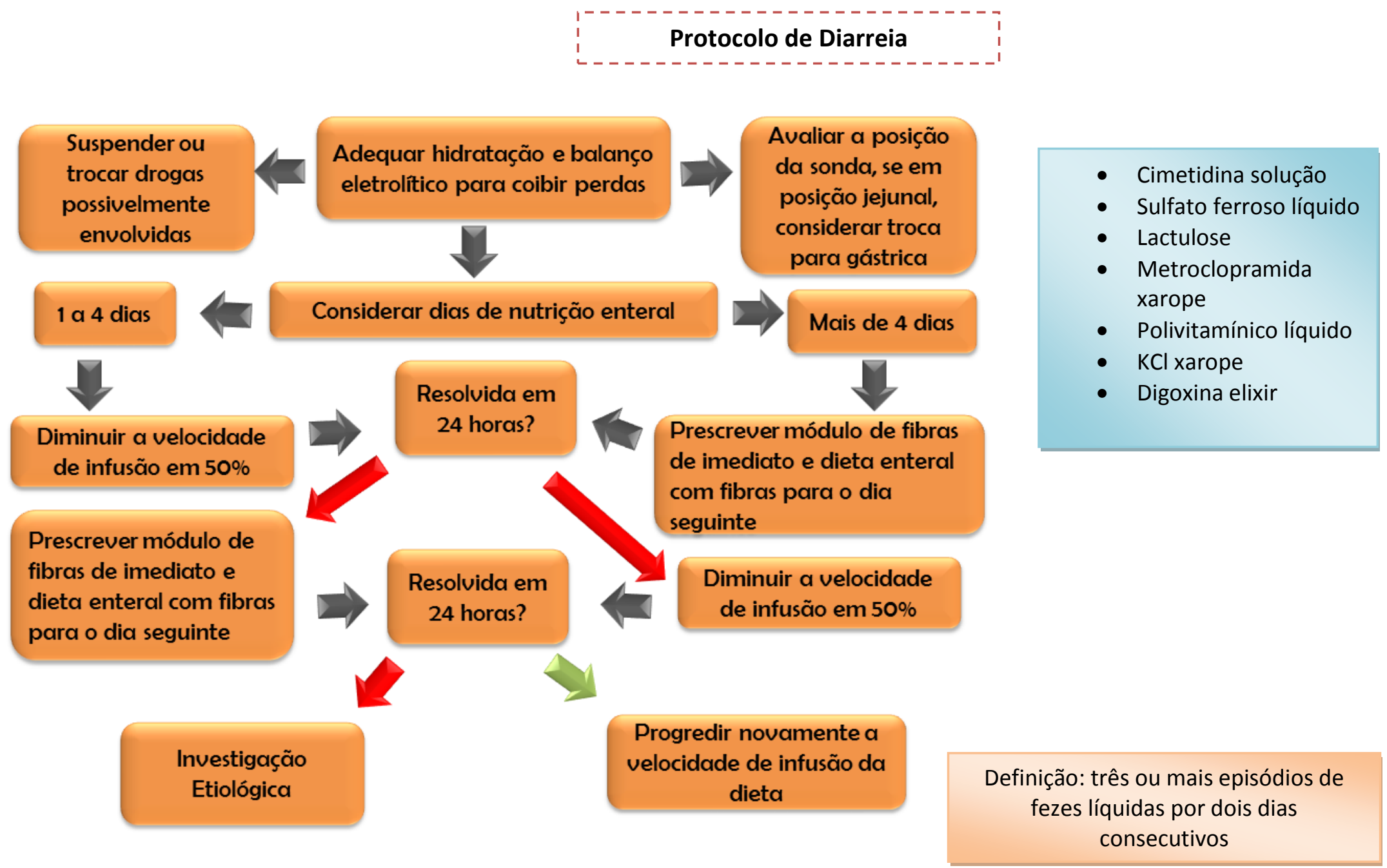


Referências Bibliográficas 


\section{REFERÊNCIAS BIBLIOGRÁFICAS}

1 Heyland DK, Novak F, Drover JW, et al. Should immunonutrition become routine in critically ill patients? A systematic review of the evidence. JAMA 2001; 286:944-953

2 Stapleton RD, Jones N, Heyland DK. Feeding critically ill patients: what is the optimal amount of energy? Crit Care Med 2007; 35:S535-540 3 Heyland DK, Dhaliwal R, Drover JW, et al. Canadian clinical practice guidelines for nutrition support in mechanically ventilated, critically ill adult patients. JPEN J Parenter Enteral Nutr 2003; 27:355-373

$4 \quad$ Wilmore DW. Why should a single nutrient reduce mortality? Crit Care Med 2002; 30:2153-2154

5 Jones NE, Heyland DK. Implementing nutrition guidelines in the critical care setting: a worthwhile and achievable goal? JAMA 2008; $300: 2798-2799$

6 Singer $\mathrm{P}$, Berger MM, Van den Berghe $\mathrm{G}$, et al. ESPEN Guidelines on Parenteral Nutrition: intensive care. Clin Nutr 2009; 28:387-400

7 Doig GS, Heighes PT, Simpson F, et al. Early enteral nutrition, provided within $24 \mathrm{~h}$ of injury or intensive care unit admission, significantly reduces mortality in critically ill patients: a meta-analysis of randomised controlled trials. Intensive Care Med 2009; 35:2018-2027

8 McClave SA, Martindale RG, Vanek VW, et al. Guidelines for the Provision and Assessment of Nutrition Support Therapy in the Adult Critically III Patient: Society of Critical Care Medicine (SCCM) and American Society 
for Parenteral and Enteral Nutrition (A.S.P.E.N.). JPEN J Parenter Enteral Nutr 2009; 33:277-316

9 De Jonghe B, Appere-De-Vechi C, Fournier M, et al. A prospective survey of nutritional support practices in intensive care unit patients: what is prescribed? What is delivered? Crit Care Med 2001; 29:8-12

10 Martins JR, Shiroma GM, Horie LM, et al. Factors leading to discrepancies between prescription and intake of enteral nutrition therapy in hospitalized patients. Nutrition 2011

11 Arabi YM, Haddad SH, Tamim HM, et al. Near-target caloric intake in critically ill medical-surgical patients is associated with adverse outcomes. JPEN J Parenter Enteral Nutr 2010; 34:280-288

12 Sigalet DL, Mackenzie SL, Hameed SM. Enteral nutrition and mucosal immunity: implications for feeding strategies in surgery and trauma. Can J Surg 2004; 47:109-116

13 Moore FA, Feliciano DV, Andrassy RJ, et al. Early enteral feeding, compared with parenteral, reduces postoperative septic complications. The results of a meta-analysis. Ann Surg 1992; 216:172-183

14 Bozzetti F, Braga M, Gianotti L, et al. Postoperative enteral versus parenteral nutrition in malnourished patients with gastrointestinal cancer: a randomised multicentre trial. Lancet $2001 ; 358: 1487-1492$

15 Berger MM, Pichard C. Best timing for energy provision during critical illness. Crit Care 2012; 16:215

16 Casaer MP, Mesotten D, Hermans G, et al. Early versus late parenteral nutrition in critically ill adults. N Engl J Med 2011; 365:506-517 
17 Kushner RF, Thorp FK, Edwards J, et al. Implementing nutrition into the medical curriculum: a user's guide. Am J Clin Nutr 1990; 52:401-403 18 McClave SA, Mechanick JI, Bistrian B, et al. What is the significance of a physician shortage in nutrition medicine? JPEN J Parenter Enteral Nutr 2010; 34:7S-20S

19 ANVISA. Portaria 272: Boas Práticas do Preparo da Nutrição Parenteral. 1998.

20 Heyland DK, Cahill NE, Dhaliwal R, et al. Impact of enteral feeding protocols on enteral nutrition delivery: results of a multicenter observational study. JPEN J Parenter Enteral Nutr 2010; 34:675-684

21 Waitzberg DL. A difference must make a difference. JPEN J Parenter Enteral Nutr 2010; 34:604-605

22 Franklin GA, McClave SA, Hurt RT, et al. Physician-delivered malnutrition: why do patients receive nothing by mouth or a clear liquid diet in a university hospital setting? JPEN J Parenter Enteral Nutr 2011; 35:337342

23 Spain DA, McClave SA, Sexton LK, et al. Infusion protocol improves delivery of enteral tube feeding in the critical care unit. JPEN $J$ Parenter Enteral Nutr 1999; 23:288-292

24 Feuerwerker L, Almeida M. [Curricular guidelines and pedagogical projects: it is time for action!]. Rev Bras Enferm 2003; 56:351-352 25 Lampert, JB et al. Tendências de mudanças em um grupo de escolas médicas brasileiras. Rev. bras. educ. med. Rio de Janeiro, 2012. 
26 Lampert, JB et al. Projeto de Avaliação e Acompanhamento das Mudanças nos Cursos de Graduação da Área de Saúde CAEM/ABEM. Rio de Janeiro, 2007

27 Beck AH. STUDENTJAMA. The Flexner report and the standardization of American medical education. JAMA 2004; 291:2139-2140 28 Okubo $\mathrm{Y}$, Ishiguro $\mathrm{N}$, Suganuma $\mathrm{T}$, et al. Team-based learning, a learning strategy for clinical reasoning, in students with problem-based learning tutorial experiences. Tohoku J Exp Med 2012; 227:23-29

29 Minard G, Kudsk KA, Melton S, et al. Early versus delayed feeding with an immune-enhancing diet in patients with severe head injuries. JPEN J Parenter Enteral Nutr 2000; 24:145-149

30 DL W. Indicadores de Qualidade em Terapia Nutricional. Sao Paulo: ILSI, Brasil, 2008

31 Kelly TW, Patrick MR, Hillman KM. Study of diarrhea in critically ill patients. Crit Care Med 1983; 11:7-9

32 Finfer S, Chittock DR, Su SY, et al. Intensive versus conventional glucose control in critically ill patients. N Engl J Med 2009; 360:1283-1297 33 O'Grady NP, Alexander M, Dellinger EP, et al. Guidelines for the prevention of intravascular catheter-related infections. Centers for Disease Control and Prevention. MMWR Recomm Rep 2002; 51:1-29

34 Knaus WA, Draper EA, Wagner DP, et al. APACHE II: a severity of disease classification system. Crit Care Med 1985; 13:818-829 
35 Blackburn GL, Bistrian BR, Maini BS, et al. Nutritional and metabolic assessment of the hospitalized patient. JPEN J Parenter Enteral Nutr 1977; $1: 11-22$

36 Organization WHO. Obesity: preventing and managing the total epidemic. Report of a WHO Consultation Group.,1997

37 Detsky AS, McLaughlin JR, Baker JP, et al. What is subjective global assessment of nutritional status? JPEN J Parenter Enteral Nutr 1987; 11:813

38 Mackenzie SL, Zygun DA, Whitmore BL, et al. Implementation of a nutrition support protocol increases the proportion of mechanically ventilated patients reaching enteral nutrition targets in the adult intensive care unit. JPEN J Parenter Enteral Nutr 2005; 29:74-80

39 Doig GS, Simpson F, Finfer S, et al. Effect of evidence-based feeding guidelines on mortality of critically ill adults: a cluster randomized controlled trial. JAMA 2008; 300:2731-2741

40 Weinsier RL, Boker JR, Brooks CM, et al. Nutrition training in graduate medical (residency) education: a survey of selected training programs. Am J Clin Nutr 1991; 54:957-962

41 Mullen JT, Moorman DW, Davenport DL. The obesity paradox: body mass index and outcomes in patients undergoing nonbariatric general surgery. Ann Surg 2009; 250:166-172

42 Alberda C, Gramlich L, Jones N, et al. The relationship between nutritional intake and clinical outcomes in critically ill patients: results of an 
international multicenter observational study. Intensive Care Med 2009; $35: 1728-1737$

43 Rubinson L, Diette GB, Song X, et al. Low caloric intake is associated with nosocomial bloodstream infections in patients in the medical intensive care unit. Crit Care Med 2004; 32:350-357

44 Alp E, Guven M, Yildiz O, et al. Incidence, risk factors and mortality of nosocomial pneumonia in intensive care units: a prospective study. Ann Clin Microbiol Antimicrob 2004; 3:17

45 Soguel L, Revelly JP, Schaller MD, Longchamp C, Berger MM. Energy deficit and length of hospital stay can be reduced by a two-step quality improvement of nutrition therapy: the intensive care unit dietitian can make the difference. Crit Care Med 2012; 40:412-419

46 Cahill NE, Heyland DK. Bridging the guideline-practice gap in critical care nutrition: a review of guideline implementation studies. JPEN J Parenter Enteral Nutr 2010; 34:653-659

47 Jain MK, Heyland D, Dhaliwal R, et al. Dissemination of the Canadian clinical practice guidelines for nutrition support: results of a cluster randomized controlled trial. Crit Care Med 2006; 34:2362-2369

48 Adams KM, Kohlmeier $\mathrm{M}$, Powell $\mathrm{M}$, et al. Nutrition in medicine: nutrition education for medical students and residents. Nutr Clin Pract 2010; $25: 471-480$

49 Lazarus K, Weinsier RL, Boker JR. Nutrition knowledge and practices of physicians in a family-practice residency program: the effect of an 
education program provided by a physician nutrition specialist. Am J Clin Nutr 1993; 58:319-325

50 Goiburu-Bianco ME, Jure-Goiburu MM, Bianco-Caceres HF, et al. [Degree of nutritional training of intensive care physicians. A survey in public hospitals of Asuncion]. Nutr Hosp 2005; 20:326-330

51 Behara AS, Peterson SJ, Chen $Y$, et al. Nutrition support in the critically ill: a physician survey. JPEN J Parenter Enteral Nutr 2008; 32:113119 
Apêndice 


\title{
APÊNDICE
}

\section{Aprovação do Trabalho para Apresentação Oral - ESPEN 2011}

\author{
33rd ESPEN Congress \\ Gothenburg, Sweden \\ Saturday 3 September - Tuesday 6 September 2011 \\ To the attention of Mrs Melina CASTRO
}

Dear Mrs Melina CASTRO,

On behalf of the ESPEN 2011 Organising Committee, we have the pleasure to inform you th the following abstract

Submission $\mathrm{N}^{\circ}$ : ESPEN11-1410

Title: NUTRITION EDUCATIONAL PROGRAM DECREASES ICU LENGTH OF STAY

has been accepted for ORAL presentation at the forthcoming ESPEN 2011 Congress to be $h$ in Gothenburg from Saturday 3 September to Tuesday 6 September 2011.

Your abstract has been renumbered and your new programme number is: OP028

Your abstract was ranked 13 out of 488 accepted abstracts.

We look forward to meeting you in Gothenburg and remain at your service for any further information you may require.

Sincerely yours,

On behalf of the ESPEN 2011 Local Organising Committee,

Ingvar Bosaeus, President

Tommy Cederholm, Scientific Committee

Ann Ödlund Olin, Educational and Clinical Practice Committee

Elisabet Rothenberg, Treasurer 


\section{Prêmio Travel Award - ESPEN 2011}

\section{ESPEN 2011 - Travel fellowship}

Espen Scienti <espenscienti@mci-group.com> Para: melinacastro@globo.com

18 de maio de 2011 06:59

\section{3rd ESPEN Congress}

Gothenburg, Sweden

Saturday 3 September - Tuesday 6 September 2011

Dear Mrs Melina CASTRO,

I am pleased to inform you that your abstract:

Submission $\mathrm{N}^{\circ}$ : ESPEN11-1410 / New programme $\mathrm{N}^{\circ}$

Title:

NUTRITION EDUCATIONAL PROGRAM DECREASES ICU LENGTH OF STAY

accepted for presentation at the 2011 ESPEN Congress in Gothenburg has been awarded an ESPEN 2011 Travel Fellowship.

30 Travel Fellowship of EUR 500 will be given to the highest scoring abstracts of the best 30 countries, submitted by a first and presenting author below the age of 35 .

The Travel Fellowship is intended to cover part of the travel expenses. The registration fee is not included and registration therefore still needs to be done following the indications given in the notification letter for your abstract presentation.

The Award will be presented as follows:

\begin{tabular}{|l|l}
\hline Session & ESPEN Best Abstracts \& ESPEN Travel Aw: \\
\hline Session date and time & Sunday 4 September 2011, 11:15-12:00 \\
\hline Session room & Congress Hall \\
\hline Presenting author receiving the fellowship & Melina Castro \\
\hline
\end{tabular}

The presenting author will receive an award form from the Chairman of the ESPEN Scientific Committee after the" Sir David Cuthbertson Lecture".

The money will be given in cash onsite at the Speakers' Desk from Monday 5 September 2011,

$12: 00 \mathrm{pm}$ to the presenting author. A valid passport proving the age of the Travel Fellowship

winner needs to be shown. No Travel Fellowship will be distributed after the Congress.

Please be so kind to reply to this e-mail may you not be able to attend the ESPEN Congress in Gothenburg and to accept the grant

Receive our warmest congratulations on behalf of the ESPEN Scientific Committee.

We look forward to see you in Gothenburg,

On behalf of the ESPEN 2011 Local Organising Committee,

Ingvar Bosaeus, President 


\section{Carta de Submissão do Trabalho à Clinical Nutrition}

\section{A manuscript number has been assigned to YCLNU-D-12- 00051}

Clinical Nutrition <espenjournals@espen.org>

26 de janeiro de 2012 15:00

Para: melinacastro@globo.com

Ms. Ref. No:: YCLNU-D-12-00051

Title: "Education program on medical nutrition and length of stay of critically ill patients"

Clinical Nutrition

Dear melina,

Your submission "Education program on medical nutrition and length of stay of critically ill patients" has been assigned manuscript number YCLNU-D-12-00051.

To track the status of your paper, please do the following:

1. Go to this URL: http:/lees.elsevier.com/yclnu/

2. Enter your login details

3. Click [Author Login]

This takes you to the Author Main Menu.

4. Click [Submissions Being Processed]

Thank you for submitting your work to Clinical Nutrition.

Kind regards,

Nicolaas E.P. Deutz, MD, PhD

Editor-in-Chief

Clinical Nutrition

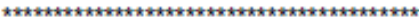

Please note that the editorial process varies considerably from joumal to joumal. To view a sample editorial process, please click here:

http:/lees.elsevier.comveeshelp/sample editorial process.pdf

For any technical queries about using EES, please contact Elsevier Author Support at authorsupport@elseviercom Global telephone support is available 24/7:

For The Americas: +1 8888347287 (toll-free for US \& Canadian customers)

For Asia \& Pacific: +81355615032

For Europe \& rest of the world: +35361709190 